\title{
THE FLOW OF NARRATIVE IN THE MIND UNMOORED: AN ACCOUNT OF NARRATIVE PROCESSING
}

\begin{abstract}
Verbal narratives provide incomplete information and can be very long. Yet readers and hearers often effortlessly fill in the gaps, and make connections across long stretches of text, sometimes even finding this immersive. How is this done? In the last few decades, event-indexing situation modelling and complementary accounts of narrative emotion have suggested answers. But despite this progress, comparisons between real life perception and narrative experience might underplay both changes to our model of the world_in narrative processing-, and the role of reader emotions which are unrelated to characters. I reframe narrative experience in predictive processing and neural networks, capturing continuity between fiction, perception and states like dreaming and imagination, through the flexible instantiation of concepts. In this frame, narrative experience is more clearly revealed as a creative experience that can share some of the phenomenology of dreams.

KEYWORDS

stories; narrative; situation model; event indexing; emotion; neural network; predictive processing; creativity.
\end{abstract}

$\underline{\text { Introduction }}$

The tale of two men who went to look for Old Man Furry. 
And they were strong, both of them, and the one had killed many bears, but the other had not hunted bears before, and he was afraid, and untrained. And when they found Old Man Furry, he was so angry that he rushed upon them in an instant, and they jumped behind a big pine tree (Turi, 1931, p.128).

How might the Sami audience listening to this story have known why the men jumped behind a tree? How did they remember, as the story continued, that only one was an experienced hunter? And why might they have kept listening? These questions can be framed as: how do we infer missing information from a narrative text? how do we connect information across the text so as to experience it as coherent? and why can stories be immersive, rendering us indifferent to our environments and usual trains of thought?

To answer these questions, I begin with a summary of event-indexed processing leading to situation models, currently the dominant account of verbal narrative processing. I suggest that despite many strengths, this account of narrative processing is constrained by by a separation between inferred information and emotion-. I suggest a way to redescribe narrative processing using predictive processing (PP) in a high dimensional vector space, allowing a holistic 'single computation' of all aspects of narrative experience (Clark 2016, 296). This approach recognises the existence of the situation model (SM) as one level of memory representation arising from narrative processing. Skeletal event sequences identified by anthropologists or oral narrative, used after the event to retell/adapt stories, for example, bear some resemblance as SMs (Bauman 1986, chapter 5; Aarne and Thompson, 1928). It is not the only level, but I argue that the aspects of narrative processing relating to other levels of representation must be recruited to explain the 
SM level; that the inferences leading to an SM must draw on the full range of narrative experience The article offers a holistic account of narrative processing looking at the dynamic interactions of emotion and inference and the ways they depart from real world perception. Seen like this, narrative processing can not only simulate the world, but imaginatively remodel it.

\section{$\underline{\text { Situation models and event indexing }}$}

In the 1960s researchers on narrative often assumed modular models of language processing, representing the text's linguistic form rather than directly representing content (Katz \& Postal, 1964; Blumenthal, 1967; Sachs, 1967). Bransford and colleagues challenged these assumptions in the early 1970s, showing how spatial representations are needed to process sentences like this one: "Three turtles rested on a floating log and a turtle swam beneath them". They concluded that sentences should not be "viewed as linguistic objects to be remembered" but as "information which [people] can use to construct semantic descriptions of situations" (Bransford, Barclay \& Franks, 1972, p.194).

These findings were followed in the 1980s by Johnson-Laird's work (1983) on mental models and van Dijk and Kintsch's (1983) on situation models. Johnson-Laird argued that "human beings understand the world by constructing working models of it in their minds,", models which "are simpler than the entities they represent" (Johnson-Laird, 1983, p.10). Van Dijk and Kintsch proposed a distinction between "the text representation proper" and "a model that the reader or hearer constructs about the relevant information for the adequate comprehension of the text" (Van Dijk \& Kintsch 1983, p.337). This combined body of work suggested that verbal narrative processing, using spatial representations, enables the creation of SMs (Morrow, Greenspan \& Bower, 1987). This does not commit SM advocates to the claim that 
SMs are the only level of memory representation produced by narrative processing, although, as Mar \& Oatley observe (2008, p.174), SMs can explain memory for text narrative at both automatic (Gerrig \& O’Brien, 2005; McKoon \& Ratcliff, 1998) and conscious, intentional levels (Graesser et al, 1994), and support inferences arising not just from spatial relationships, but also of characters' short and long term goals (Glenberg et al, 1987; Trabasso \& Wiley 2005).

Narrative text was also increasingly analysed in hierarchically organised chunks. In Van Dijk and Kintsch's "macro structure theory, at a macro level and has a rule governed relationship to micro episodes (van Dijk, 1977; Kintsch, 1977; Kintsch \& van Dijk, 1978). Emerging “story grammar" theories also involved hierarchical organisation around characters and their goals (Rumelhart 1975, 1977; Meyer, 1975; Thorndyke, 1977; Mandler \& Johnson, 1977; Stein \& Glenn, 1979).

These hierarchical organisations of narrative resembled new accounts of event perception. Events are bounded, hierarchically nested, segments of time. “Opening a door $_{2}$ ", for example, can be one event within the higher order event of "arriving at a party” (Newtson, 1973; Zacks \& Tversky, 2001). An event boundary is perceived when there is simultaneous change across a set of key dimensions (Zacks et al, 2007). The "event indexing model" provided an explanation of how narrative processing could lead to SMs_-(Zwaan, Langston \& Graesser, 1995; Zwaan, Magliano \& Graesser, 1995). In what follows, I suggest that replacing this limited number of commonsense dimensions with a high dimensional vector space can improve our understanding of the relationship between event segmentation, the creation of SMs and narrative experience more broadly. 
The existing dimensions of event change indexed by readers are: which character is this?; change in characters' goals; new information about causation; change in location; change in the time of events narrated; and change in characters' interactions with objects (Zwaan \& Radvansky, 1998; Zacks, Speer \& Reynolds, 2009). This is the model is used by most researchers working on narrative processing today (for examples, see Zacks, 2015; Chow et al, 2014; Muijselaar, 2015). The production of SMs can provide readers and hearers of verbal narrative with a global sense of a story, by organising information around the key dimensions (Sanford \& Emmott 2013, pp.37 - 38). The production of SMs also relates to narrative inferences: the situation builds in knowledge of the world ${ }_{2}$ which is not always explicit in the text. The process of SM construction has been used to explain immersion in verbal narrative through embodied language processing drawing on behavioural and neuroimaging work in embodied language processing such as that of Reddy (2010), Hauk (2008), Barsalou (2008), Glenburg \& Kaschak (2002), Speer et al (2007) and others (Zwaan, 1999). These approaches to narrative processing are compatible with, and sometimes supported by, accounts of emotion and empathy in response to film and verbal narrative by Tan, Sanford \& Emmott and others (Tan 1994; Sanford \& Emmott, 2013, 44, pp.191 - 232).

By moving from modular models of verbatim text representation, event indexing and situation modelling have revealed shared elements in narrative processing across media, including film (Zacks, 2015; Speer, Zacks and Reynolds, 2007; Magliano, 2012), and a comparative framework for variations in narrative processing between individuals (Kurby, 2011; Bohn-Gettler, 2011). They make clear predictions, for example that processing at event boundaries in the text will be slower (Zacks, Speer \& Reynolds, 2000). By recruiting embodied language processing to 
verbal narrative, they share in a broader move towards embodiment in the cognitive sciences (Clark, 1997; Clark, 2016, pp. 109-240).

These gains have been won by recruiting the resources of everyday perception (Zacks, 2015). However, the current account of the processing behind SMs may neglect the status of verbal narrative as an artefact, a product of human behaviour, whose processing may be comparable to cognition of, say, music or handwriting (Knoblich et al, 2002; Overy \& Molnar-Szakacs, 2009). In what follows, I exploit the flexible frameworks of PP and neural networks to explore differences between the narrative processing that produces SMs, and everyday perception

I illustrate my account with the case of a child listening to a fairy tale. Fairy tales come closer to a universal narrative experience than the texts used in many experiments; they are found in diverse cultures and periods, and are accessible to very young hearers with a minimum of prior skill in narrative comprehension (Tehrani, 2003, pp.1-11; Aarne and Thompson, 1928).

\section{$\underline{\text { Listening to The Juniper Tree }}$}

The Juniper Tree was collected and edited by the Grimm brothers in the early nineteenth century, and has several cognates in other cultures (Grimms 1973, 314332; Aarne and Thompson 1928, tale type 720). Very young children, from a wide range of cultures, frequently become immersed in stories like this, as the tales' persistence across time and place, and with young audiences, suggests (Tehrani, 2003, pp.1-11; Whitehead 1999, pp.104-107). I analyse the opening of The Juniper Tree in the light of existing approaches to the processing that leads to SMs and discuss some problems this analysis identifies: 
It is a long time ago now, as much as two thousand years maybe, that there was a rich man and he had a wife and she was beautiful and good, and they loved each other very much but they had no children even though they wanted some so much, the wife prayed and prayed for one both day and night, and still they did not and they did not get one. In front of their house was a garden and in the garden stood a juniper tree. Once, in wintertime, the woman stood under the tree and peeled herself an apple, and as she was peeling the apple she cut her finger and the blood fell onto the snow. "Ah," said the woman and sighed a deep sigh, and she looked at the blood before her and her heart ached. "If I only had a child as red as blood and as white as snow." And as she said it, it made her feel very happy, as if it was really going to happen (Grimms, 1973, pp.314-315).

There are several examples here of the five dimensions of change (time, space, causation, motivation and protagonist; Zwaan \& Radvansky 1998): longing for a child and peeling an apple (goals); and "in winter" or "under the tree" (changes in time and location). Situation modelling of verbal narrative involves an embodied approach to modelling space, and event-indexing in narrative involves simulating embodied experiences of real life environments (Zacks, 2015, 449). These embodied experiences can be seen as a source of emotion, either intrinsic to creating the SM (Zwaan 2009), or complementary to it (Sanford \& Emmott, 2012, pp.191 - 232). The potential for embodied responses to the text through actions - peeling an apple, cutting a finger, looking at blood on snow - can help, then, to explain immersion if it occurs.

But here also lies a problem. If an embodied response to a text about cutting a finger and bleeding generates emotion, the emotion ought to be negative, even 
distressing, particularly for child hearers. The character's happiness might then be experienced as incoherent. Yet the success of this tale, particularly with children, included repeatedly in editions of Grimms' tales over 200 years, suggests that it is not.

Generic experience of fairy tales might help hearers to bridge the gap between real life experience and narrative. Genre knowledge could certainly prepare the child hearer for departures from real world experience, such as minimally counterintuitive concepts, like the talking bird who appears later (Norenzayan 2006; Thompson 19551958). But generic knowledge cannot filter "happiness" from the range of relevant potential responses to injuring one's finger; a generic example like Sleeping Beauty could even make this harder (Kibbe et al, 2017).

An alternative solution to explain how processing produces the relevant information for an SM might be to distinguish reader emotion from the emotion in response to character alone. Moves in this direction have been made by Tan (1994) and Sanford \& Emmott (2013). Tan attributes to readers/viewers not, or not just, the simulated emotions of characters, but the emotions of an impotent witness of the characters, and argues that these emotions enable, rather than just arising from, predictive inferences (Tan 1994, p.184). Sanford and Emmott suggest that "scenario mapping" and embodied responses allow the emotions of characters to be "built into" readers' "mental representations". These lead to reader emotions, modulated by approval, liking or closeness to the characters into macro narrative structures of curiosity, surprise and suspense, which can generate arousal jags and boosts (pp.196, 207; drawing on Berlyne 1960, 1971; Brewer and Lichtenstein, 1982; Sternberg 1978, 2003). 
On their own, however, these accounts cannot solve the problem with The Juniper Tree. Children are frequently impotent witnesses of scenes involving adults, and it is not clear that in this case the child's response to seeing an adult woman cut her finger would enable her to predict the woman's happiness. This passage may create distance rather than Sanford and Emmott's closeness - the characters exist in an unspecified place and a distant and unspecified time. They have morally attractive characteristics - they love one another, they would love a child - but they perform no actions in this passage which are open to moral evaluation either way. It would be hard to say that a four-year-old child has enough here to generate liking, dislike or (dis)approval. This would be hard to settle without empirical investigation, but it is at least questionable that emotions arising from closeness, approval and liking, in turn leading to hopes and fears, and from there to arousal jags and boosts, can explain why very young children can are not puzzled by the woman's response to a cut finger.

A holistic account of the hearer's emotional responses to narrative, however, can build on Tan's alertness to the role of reader/hearer impotence in narrative experience, and of the distinction between reader emotion and character emotion. In perception, we act on the environment to deepen our understanding of it, if only through eye saccades (Grimes, 1996; Smith and Henderson, 2008; Henderson, 2003). In narrative experience, however, we are unmoored from our immediate environment; the hearer of a narrative cannot act on the stimulus to derive greater sensual information about the scene depicted. Both perception and narrative may engage the same machinery of predicting incoming signals, as I discuss below (Clark 2016; Gerrans 2014). But the concepts instantiated by language cannot always be interrogated in the same sensory depth as those arising from perception and action embedded in an environment. Instead, they may be experienced in relationship to one 
another, isolated from a shared environment. Even the eye saccades crucial to film comprehension can be highly determined by lighting, camera angle, montage etc, and the film is not fully available for ecological interrogation through the viewer's bodily location and action (Cutting et al 2011; Hasson et al 2008; Loschky et al 2015; Gibson 1979).

In the first part of the passage from The Juniper Tree, the hearer encounters the concepts of a rich man, a good and beautiful wife, the absence of a child, longing for a child and praying for a child. The hearer's passivity, her inability to act on the stimulus, means that none of this information can be further probed. The man and the wife may give rise to embodied neural effects in relevant sensory and motor areas, but these are not instantiated in relation to the child's perceiving body. Encountering a "rich man" face to face, for example, would instantiate a power relationship with a child, with embodied consequences (Fiske et al, 2016). Encountering the concept through language, however, potentially neutralises such effects and frees the set of concepts to interact in novel ways. The "feature tuning" of mental images in response to nouns (such as "man" and "wife") can vary considerably with verbal context (Mitchell \& Cusack, 2016, pp. 4 - 7). "Man" and "wife”, dis-embedded from a rich scene, might mutually influence each other's instantiations. "Rich" in conjunction with "beautiful" might give prominence to the beautiful belongings that wealth can buy, rather than, say, the cruel behaviour that wealth can sometimes enable.

The interactions of this small set of concepts then ("man", "wife", "rich", "beautiful"), when experienced passively (in the sense that the body cannot glean additional sensory information), in isolation from an environment, and unmoored from a perceiving body, may subtly modify the hearer's statistical model of the world's hierarchy of proximal and distal causes and effects (Clark, 2016; Kirchhoff 
2018). For example, the conjunction of "good", "rich", "loving" and "beautiful" with "lack" and "longing" may point to a rightly ordered world that has somehow gone wrong; the blessed can also be unblessed. Similarly, the imagery of blood on snow can be separated from the embodied experience of the cut, so that the blood and snow - again, pushed together through isolation from a perceiving body in a richer environment - can be instantiated through contrasts of colour, temperature and texture. As their other features drop out, the aesthetic effect of this combination may dominate the potential for distress in a child's simulation of cutting herself and watching herself bleed, recalling Miall and Kuiken's distinction between "narrative emotions" (relating to characters) and "aesthetic emotions" (Miall \& Kuiken, 1994, 1999). The isolation, and then conjunction, of juniper tree, snow, blood, apple, aesthetic thrill, and a sudden transition from longing to joy then become causally implicated in the subsequent conception of a child.

This analysis shows the kind of thing that could happen, rather than what must happen, but it is enough to raise a doubt that the existing account of event segmentation, leading to SMs, using a fixed set of commonsense dimensions, alongside theories of emotional response to characters, can explain this and similar narrative inferences which are needed for the SM. In the next section I explore the mechanisms by which this hearer might be immersed in narrative through the unfolding of a subtly unfamiliar trajectory; a succession of points in a multidimensional space.

$\underline{\text { Stratified versus holistic organisation of narrative information }}$

Zwaan and Radvansky predict that there may turn out to be more than five narrative dimensions involved in the production of SMs (p.167; see Rapp, 2001 for a proposed addition). But there is currently no suggestion that the number extends 
beyond common sense concepts such as "location" or "goal". If "Bill is very tall" turns out to be irrelevant to subsequent situations, it is "relegated" and excluded from "subsequent situation models". If the reader later finds that "Bill could see over everyone's head", the information can be retrieved and "stored directly with the token in the model" (Zwaan and Radvansky, 1998, pp.11, 17, 19 - 20).

Zwaan and Radvansky are not proposing, then, a division of information into "modelled" and "discarded". But their account does imply that incoming information can and should be identified as having greater or lesser importance for the model. If all the incoming information could immediately be incorporated in the model without compromising it, there would be no need to monitor the dimensions. The power of an SM is not just, as Zwaan and Radvansky correctly point out (pp.162-163), that it is more efficient than storing representations of verbatim text, but that it is more efficient than treating all of the information provided by verbatim text as equally important. While other levels of narrative memory and representation may operate outside an informational hierarchy of this kind, it would seem to be essential for event segmentation and the formation of SMs.

I suggest, however, that in the case of The Juniper Tree, dividing the textual information in this way can only be done by sacrificing, among other things, the contribution of emotion to narrative inference and coherence. Look again at the quotation above, from, "In front of their house...". To update her SM as she hears this passage, the child hearer must identify information relevant to goals and causes, two of Zwaan's and Radvansky's dimensions; that the woman sighed, and that her heart ached, not because her finger was sore or her apple spoiled, but because the experience seemed somehow relevant to her desire to have a child. 
But the fine detail of the "irrelevant" information, I suggest, is important to emotion, and the role of emotion in processing. In combination, these elements configure an emotional experience which has no counterpart in the child's real life experiences of apples and knives, an experience which reveals that the woman's longing will be fulfilled because, in mysterious ways, nature wills it so.

We can illustrate this point in a different way by reverse engineering a segment of Zwaan and Radvanksy's illustration of the processing behind SMs - "Peter took the elevator to the fifth floor. He went to talk to his professor":

...When reading the first sentence, the reader creates a situation model involving a token that represents a male individual named Peter who rides an elevator for as yet unknown reasons. We assume that the reader infers that Peter is in a building and that the event took place before the moment of utterance of the sentence....This [second] sentence is integrated with the first one on several dimensions. First, the pronoun is a cue to the comprehender to look backward...in the integrated model for an appropriate referent. This referent is found in Peter, who is the only available referent and shares the feature "male". Second, a goal is constructed ("went to" suggests intentionality...). Third, the absence of a shift in tense or any other explicit temporal marker indicates that we are still in the same temporal interval... Fourth, the absence of a spatial marker indicates we are still in the same spatial region.... Fifth, a second token is created representing the professor. The reader probably also infers that Peter is a student. This is the content of the current model at Time $t_{2}$.

This can be represented schematically-: 


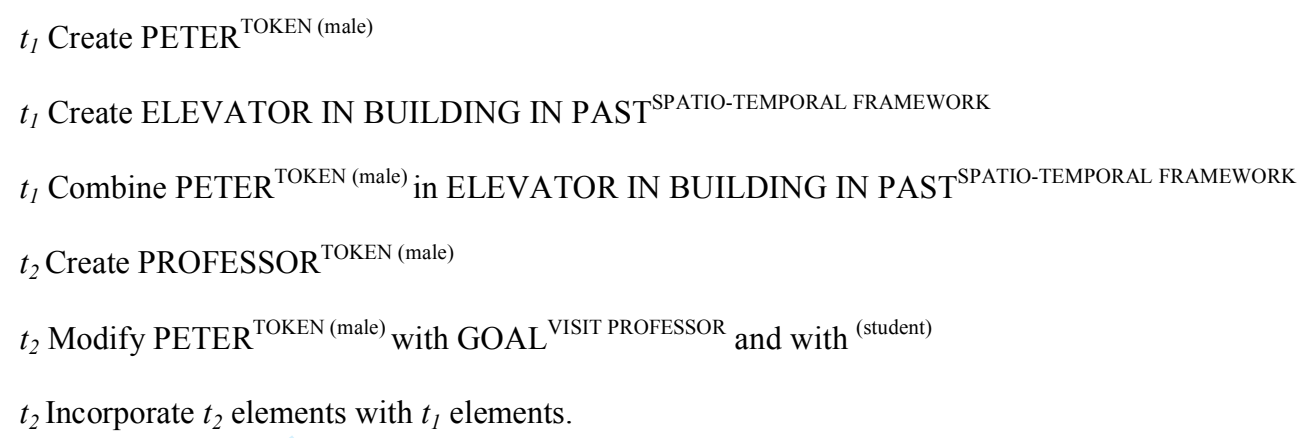

If we use this set of instructions to generate a new text, one possibility of many is this: "Peter rode in the elevator up, up, up. His professor waited as Peter came nearer and nearer." This text is different from the initial one in many ways, from the professor waiting, to the absence of "the fifth floor". But it is as compatible with the situation model above as the original. The reader's emotion, however, is likely to be different. The stylistic emphasis on the changing relative distance between Peter and the professor may create an element of anxious anticipation. Emotion arising from verbal form may underpin the inference of information, rather than the reverse (compare Barrett and Bar, 2009). The verbal form suggests that either Peter or the Professor has something to fear from the encounter. Peter's goal may not be related to their roles of student and professor; Peter may not be a student at all if his relationship to the professor may be that of, say, victim or aggressor. The repetitions of "up" and "nearer" do not provide new information on the SM's dimensions. Yet their emotional impact on the reader is important for identifying precisely the information - such as characters' goals - which an SM is intended to capture. While the SM itself need not capture reader emotion, the processing leading up to it must if the information in the $\mathrm{SM}$ is to be correct (for earlier work pointing in this direction, see McNamara \& Magliano, 2009 and Graesser, Olde \& Klettke 2002). 
Suppose the repetitions in "up and up" and "nearer and nearer" cause fear, telling the reader that either Peter or the professor has a sinister goal. Could this simply mean a different "goal" node than the model of the first passage? The spatiotemporal information still models Peter in an elevator and the professor in a room, just as in the first case.

But if the repetitions of "up" and "nearer" simply switch the goal node from "visit professor, probably in relation to studies" to "go to professor's room, not clear why, but this may involve danger either to Peter or the professor", does this bundle of information, a bundle which must be expanded if it is to include all the implications of fear, deserve the name of "goal node"? Recall that the strength of SMs is saving the hearer or reader from remembering not only all the verbatim text, but all of the information conveyed by that text. If the model is to incorporate all the implicit information generated by emotion, it will be burdened with even more information than that of the verbatim text. If emotion is treated as information encoded in the text, then it cannot be incorporated in an SM. Yet, as we have seen, emotion may be crucial to help a child make correct inferences about texts like The Juniper Tree. An improved account of narrative processing, then, will be holistic in its approach to information, and distinguish more clearly between the experiential aspects of perceiving something, and those of hearing or reading about it.

A first step is to rethink the processing behind SMs as structured not by five or six common sense dimensions, but by dimensions too many to enumerate, resisting commonplace psychological categorisation. A neural network model of processing in this high dimensional vector space (explained below) can capture recurring experiences in processing a given text, including the effects of verbal patterning, emotion and the perception of language as agent guided behaviour. Characterising 
those recurrent, downward projections as predictive can also suggest a convincing story about immersion in a flow of inner states, and explain overlaps in phenomenology between dreaming and narrative immersion.

High dimensional vector spaces and verbal narrative

Think of a word as a sequence of sounds, where each sound has the potential to differentially activate every cell in an array. Each phoneme will come to be associated with a different pattern, or vector, of activation. The array activates another, higher, array through a set of connecting links or synapses, which in turn activates the next, and so on. The varying strengths or weights of these connections between layers have been determined by past experience, and form matrices which transform the vectors and allow recognition of groups of sounds, then words, phrases, clauses, sentences and so on (Rumelhart \& McClelland, 1986; Churchland, 2012; Jordan, 1986).

As well as these upward connections, each array has downward connections to the one below. This means that the effect of one input on the system can affect the way the next input is received, so that frequently repeated sequences of inputs are more easily recognised than others (Churchland, 2012, pp.165-170). At a certain level or levels, the points in the vector space initially activated by speech sounds move into spaces generated by a much wider range of stimuli associated with those speech sounds. On hearing the sounds for the word "apple", for example, a processing journey begins which, depending on the context, may end in an area of vector space overlapping, though not identical with, that activated by seeing a real apple (Reddy et al, 2010).

Now let us revisit The Juniper Tree. How does the hearer make the link between the interactions of a cluster of concepts (juniper, apple, blood, snow), the 
emotion associated with those interactions, and a character's conception of a longed for child? At first blush, adopting a vector space framework takes us no further forward with this problem. The world model of interacting causes built into this framework is embedded in the matrices of connection weights, and altering these weights is a slow and cumulative process, a matter of weeks or years, not the seconds or fractions of seconds involved in responding to a section of a story. How can hearing a brief text, or fragment of text, temporarily modify these weights to accommodate a different analysis, one in which cut fingers activate representations involving beauty and yearning rather than pain and distress, for example?

One possibility is that instead of modifying the matrices of weights, the recurrent, downward connections can modify the stream of inputs. In the case of The Juniper Tree, all of the effects of the text to date influence the pattern of downward connections in ways that affect the upward impact of new inputs. The succession of states and their direction of travel form a trajectory through vector space. In what follows, I suggest that verbal narratives can stimulate trajectories of this kind that depart from normal perceptual experience, while staying within the bounds of a preexisting world model.

Behavioural, neuro-psychological and neuroimaging evidence suggests that “concepts are flexible, distributed representations comprised of modality specific conceptual features" (Kiefer and Pulvermüller 2012, 805). This flexibility is consistent with accounts by Paul Churchland and Margaret Boden characterising the reconceptualization of an input in the "hidden" layers of a neural network as a creative process. Each cycle of Newton's meditations on the moon could modify his existing concept a little more, until the moon is less like a wheel running on a track and more like a ball thrown by a force (Churchland 2012, pp.187-196; Boden 2004). 
The everyday experience of narrative text may similarly push us through otherwise unfamiliar trajectories in vector space.

$\underline{\text { Vector spaces and inference }}$

The extract from The Juniper Tree, typically of fairy tales (Thompson, 1946, p.8), provides minimal information about particulars of place or time. The event happened "once" and "in winter time" rather than on, say, 4 January 1822. The time, then, is indeterminate, as are the unmodified nouns "woman", "tree", "apple" and so on. Adjectival modification affects the ways in which nouns are processed (Westerlund et al, 2015; Bemis \& Pylkkänen, 2013). Each of the unmodified concrete nouns in this case, then, could potentially activate an area of vector space associated with a prototypical representation (of women, trees, apples and so on), areas which capture averages of similarity and difference across multiple dimensions, thus enabling real life recognition of a particular woman, tree or apple by its location relative to the average. Coming as they do in a sequence, the downward, recurring connections generated by these nouns create a context in which singular entities (the particular woman, tree, apple of the story) are reconceptualised as prototypical ones (compare the comments on style and prediction in Kuperberg \& Jaeger, 2016, p.48). The later nouns "blood" and "snow" arrive in, and reinforce, a landscape of prototypes. A real life encounter with objects and people that all coincided precisely with the average of their type might create a sense of the uncanny, and "seemingly invite a supernatural explanation” (Bouvet and Bonnefon, 2015, p. 956).

A second contextual effect could arise from repeated syntactic patterns. The text consists mainly of additive clauses - "and as she was peeling....and the blood fell...and she looked... and her heart ached" - with little of the subordination ("she cut her finger causing the blood to fall", "her heart ached because...") that can point 
directly to causal relationships (Morera et al, 2017). In perception, a repeated temporal sequence can have a strong, sometimes misleading, association with causality (Churchland, 2012, pp.177-178). However, the recurrent connections generated by a repeated syntactic pattern of additive clauses could undo this because the hearer is not free to probe causation as she would in a richer environment.

By contrast, perception of a scene like this in a real world, rich environment would be structured by causal relationships. The appearance of the woman would be modulated by effects of light and shadow caused by the tree and the snow (Kersten et al 1997). Spatial structure has long been understood as important to perceiving causal narrative structure (Heider 1944), just as internal scene construction is critical to both episodic memory and verbal narrative (Mullally et al 2012). In this case, in the absence of a causal structure relating many of the elements in the scene, and in a landscape of syntactically weakened causal links, other patterns of similarity and difference can interpret the relationships between inputs. The tastes and textures of apples, for example, and the texture and temperature of snow could be located in adjacent or overlapping areas of vector space, as multisensory integration (Stein et al, 1988) is released from the constraints imposed by real world stimuli. The pain of a cut might be measured against the colour and temperature of blood. In a real world scene these modality specific overlaps may be unimportant, but here, in a sparser, less defined scene, they take on new power. The synaesthetic effects of this process would, moreover, have an aesthetic reward (Ward et al, 2008).

Now let us imagine that the hearer has had many disappointed hopes, but has also experienced a powerful hope turning into a belief. The move from hope to belief, then, is a possible sequence for her, but not a necessary one. In a context coloured by the uncanny and by aesthetic reward, a context in which normal causal relations have 
been muted, this sequence (of hope turning to belief) may become the most likely path for upcoming activation (compare Clark, 2016, pp.231 - 237). The hearer can hypothesise that the woman sighs because of longing, not physical pain, without modifying her world model's matrix of weights.

\section{A vector space account of narrative coherence}

In 1990, the cognitive scientist Jeffrey Elman discussed the problems of representing time in parallel, distributed, connectionist models of cognition, similar to the neural networks outlined above. Until then, Elman explained, a common approach to the parallel processing of sequentially structured inputs, like language, had been to treat time as "an additional dimension of the input" by giving it an explicit "spatial representation". The first item in a verbal sequence could be represented in the first space in a vector, and so on. Elman argued that this approach runs into intractable problems (which I do not discuss here; Elman, 1990). Time is an explicit dimension of the input to SMs in existing accounts: a complete SM, 'stored in long-term memory after all the textual input has been processed' will consist of 'the situations at Times $\mathrm{t}_{1}$ through $\mathrm{t}_{\mathrm{x}}$ ', allowing comprehenders to 'ruminate over a story' later (Zwaan \& Radvansky 1998, 166). While not described as a spatial representation in the form of a numerical matrix, this is an approach which makes time an explicit dimension in both processing (one of the five associated with SMs) and output (the SM itself).

Instead of treating time as a dimension of the input, Elman suggested instead an implicit representation of time in which a layer of "context" cells is added to the layers of "hidden" cells. At time $t$ :

Both the input units and context units activate the hidden units; the hidden units then feed forward to activate the output units. The hidden units also feed 
back to activate the context units. (Elman 1990, p.182).

The context units modify future inputs by responding to previous inputs. In this way, time can be represented through its cumulative effects "on processing and not as an additional dimension of the input".

A "spatial metaphor for time" of the kind identified by Elman as problematic is implied by the SM's linear structure from $t_{1}$ to $t_{x}$, which ensures coherence, letting the reader 'know when the described events took place both relative to each other and relative to the time at which they were narrated' (Elman, 1990, p.181; Zwaan \& Radvansky, 1998, p.181). But are such representations of time always essential to the processing that enables SMs? If I am asked to write a reference, I might try to recall specific instances of the candidate's past behaviour. However, if I predict what my friend will order at a restaurant, I need not bring to mind all or any of the past episodes underwriting that prediction, even if I could. To test narrative comprehension, researchers need to resolve the experience of verbal narrative into actions after the event, such as answering questions about a story accurately, or retelling it (Ennemoser 2007, p. 354; Strong 1998). One way to describe this is the ability to interrogate the SM which arose from processing the narrative.

But there is another way to think about, and potentially even measure, verbal narrative comprehension: the success of a cognitive system in continually moving towards stasis in response to an incoming flow of text (Spivey, 2007, p.36 and elsewhere). A child hearer could experience this move to stasis yet still perhaps be unable, if asked, to accurately reconstruct a timeline of the story or answer questions accurately. Even scrub jays can "remember" sequences of their own actions without, presumably, being able to represent those sequences to themselves or to others 
(Clayton and Dickinson 1998, 1999; Suddendorf and Busby, 2003). As Elman points out, "The representation of time - and memory - is highly task-dependent". A potentially explicit spatial representation of time may be essential to the task of reproducing a story. But it is not necessarily essential to experiencing the flow of verbal narrative as coherent.

The Juniper Tree continues with the woman's pregnancy, her death from happiness on giving birth, and her husband's remarriage:

By the second wife he had a daughter, but the child of his first wife was a little son as red as blood and as white as snow. Now when the woman looked at her daughter she loved her so, but looking at the little boy cut her to the heart.

Not long after, the stepmother kills the boy and hides the evidence by cooking the body parts in a stew. The text never refers to her as "the stepmother" but as "the woman" or, when addressed by the boy himself, "mother": "Mother," said the little boy, "how strange and wild you look!". To avoid confusion with the real mother, and experience the story as coherent, the child hearer must remember that the real mother died and was replaced by a wicked stepmother. One solution is to tag the mother's death and the stepmother's arrival as $t_{x}$ and $t_{x+1}$, in, ready for incorporation in an SM by situating them on a timeline. But the child's experience of the text as coherent can be explained without this explicit representation of time:

\footnotetext{
And so the mother took the little boy and hacked him in pieces and put the pieces in the pot and stewed him in the sour broth. But Ann Marie stood by and cried and cried and the tears fell in the pot so that it didn't need any salt.
} 


\begin{abstract}
When the father came home he sat down to supper and said, "And where is my son?" And so the mother brought a big dish of black stew and Ann Marie cried and couldn't stop crying.
\end{abstract}

I argued above that the real mother could be generated in areas of vector space which involved the uncanny and the aesthetic effects of synaesthesia. The stepmother, on the other hand, is developed through "taking" and "hacking", and the objects surrounding her are "the pot" and "the sour broth", reinforced soon after as "a big dish" and "black stew". The difference in the areas of vector space activated in each case mean that neither a timeline of death and remarriage, nor a consistent verbal distinction between "mother" and "stepmother", are needed for the child hearer to experience the text as coherent. Indeed, at this point in the story she need not even explicitly remember that there ever was a good mother. After all, many stories, including oral epic and medieval romance, are experienced as coherent even when found, after performance, to be incoherent and flawed by "continuity errors" (Griffith, 2012).

\title{
A predictive, vector space account of narrative immersion
}

There is growing evidence that language comprehension is predictive at every level, from phonemes and words to discourse. Probabilistic processing, for example, can pre-activate words in comprehension (Delong et al, 2005). Grammatical inflections can be anticipated through semantic integration, and word meanings can be predicted on the basis of discourse context (Wicha et al, 2004; Van Berkum et al, 2005; Otten and Van Berkum, 2008). These findings are drawn from different languages, multiple linguistic levels and using varied methodologies (Kamide et al, 2003a; Kamide et al, 2003b; Knoeferle et al, 2005). 
We can, then, characterise the downward connections discussed above as predictions about the incoming verbal signal (Clark, 2016, 285-286). In a PP framework, downward hypotheses are met by upward prediction error. Patterns of prediction error simultaneously modify the next wave of downward hypotheses and allocate precision, or increased weight, to the most reliable sources of error for the task at hand. Action is integral to this cycle of hypotheses, prediction error and precision allocation, through, for example, eye saccades.

One outcome of a move to PP, or hypothesising controlled by prediction error (Clark, 2016), is a new account of relationships between cognitive states such as dreaming, hallucination, delusion and imagination (Gerrans, 2014, p. 1; Kirchhoff, 2018; Seth, 2014, p.101). In what follows I characterise hearing or reading a narrative as a cognitive state in which prediction error is limited to the incoming verbal stream, so that the hearer or reader, to successfully predict the incoming signal, must predict her own inner states, sequestering her sensorimotor responses from the machinery of the world around her.

Actions to probe the environment can help the hearer to predict the stream of words in The Juniper Tree only to a limited extent. Perhaps the storyteller has a lisp, and she must compensate for this when predicting phonemes, or perhaps he uses particular gestures in their shared space, and her predictive system might direct saccades to his face and body (Lwin, 2010). But greater attention to arm movements and sound articulation will not help her predict the states of higher levels in her own system, such as the combined effects of synaesthesia and the uncanny identified above. For these, her best - indeed her only - source of information is the trajectory of inner states arising from the experience of the text itself. It is these higher--level inner states which must be explored and probed through the mechanism of precision 
weighting. The hearer's own states become her environment as far as predicting the text goes. In this light, the potential for immersion is not surprising.

Seen like this, narrative experience in one respect resembles dreaming. Both experiences engage the mind in actively predicting an incoming stream of data, but without the body being able to act on its environment to direct that stream. Hobson and Friston characterise sleep as a state "in which internal predictions are sequestered from sensory constraints" (Hobson and Friston, 2012, p.92).

Embodied responses to language suggest that the reader or hearer of narrative may similarly find her sensorimotor system engaged while sequestered from any stimulus but the verbal stream, and inhibited from acting on any stimulus but the verbal stream (for example by re-reading a sentence, or asking a reader to pause). Narrative comprehension then, might be characterised as simultaneously active, in the sense that the system has considerable work to do on internal states as it seeks to optimise prediction and achieve stasis, and passive, in that the body has only very limited opportunities to act on its environment in pursuit of that stasis, and must develop new trajectories from existing resources to account for the succession of internal states.

The analogy between narrative immersion and dreaming should not be overdone. Narrative stimuli are artefacts, dreams are not. Readers can re-read, but dreamers cannot pause and repeat a section of a stimulus. Narrative can engage and require conscious effort at problem solving in way that dreams cannot. And readers can stop at will. But shared constraints in the two conditions may explain at least some of the dream-like phenomenology of narrative immersion.

This account of immersion does not require hearers and readers to feel emotions for characters, as some existing theories of transportation do (Gerrig, 1993; 
Green \& Brock, 2002). Fairy stories like The Juniper Tree can be immersive, but do not necessarily encourage direct emotional responses to characters. Stock characters are central, not peripheral, to this and other oral genres (Propp, 2010; Lord, 2000). The same could be said of immersive responses to a range of other non-realist (in Barthes' sense of 'the reality effect'; 1986) fictions, which some readers/hearers find immersive, from Homer to Virginia Woolf.

The sketch above does not assume immersion always happens, just as existing models do not assume that comprehension always happens. Some stories, or some readers, might reveal an easy to predict causal structure involving little emotion, so that attention wanders. With others, prediction might be too hard to permit flow, at least on a first reading (Csikszentmihalyi, 1990). But a predictive account can explain the possibility of later immersion through practice and re-reading, as readers grow more expert at predicting a text, like Joyce's Ulysses (a tough first read for many, an immersive re-read for some), an author or a genre (Kibbe et al, 2017).

$\underline{\text { Problems }}$

There are potential problems in at least three areas: the cognitive framework; a role for conscious reflection; and empirical testing.

I have drawn on Clark's (2016) account of Bayesian predictive processing implemented in a neural network. Clark himself has identified some problems with both elements (pp.297-300). Alternative approaches to probabilistic inference have been explored in both neural simulations and in studies of the biological brain (Egner \& Summerfield, 2013). Neural networks may not be the best, or even a possible, architecture for a generative, probabilistic approach to cognition (Hinton, 2006; Wacongne et al, 2012). 
Another concern is the role of higher domain areas, such as conscious verbal reasoning, in probabilistic, generative predictive processing (pp.299-300). I have argued that implicit, rather than explicit, representations of time may be enough to support at least some narrative processing. But conscious reflection on narrative experience may be needed to retell, interpret and experience stories as meaningful and instructive. Reducing the role of reflection may mean missing some of the point of narrative in the first place (Mulhall, 2007; Malinowski, 1926).

A third issue concerns making and testing predictions. Spivey and others have pioneered methods to measure language processing in real time (Spivey, 2007, pp.7477). In combination with real time measures of affect, these could test predictions about how, for example, affect guides hearers towards inferences in narrative processing. Rapid advances in the verbal classification of images by neural networks suggest that upending these networks to produce images from text (as readers do) may reveal surprising implicit causal frameworks (Mordvintsev, 2015).

$\underline{\text { Conclusion }}$

Describing narrative experience in a PP, neural network framework reveals that the range of benefits we reap from stories may be both more subtle and more widely diffused than we realise. Narrative experience may be a highly creative process, reconceiving the world as recognisable, yet with a different causal structure to that in which we live and move and have our being.

\section{$\underline{\text { References }}$}

Aarne, A. and Thompson, S. (1928). Types of the Folktale. Helsinki: Suomalainen Tiedeakatemia.

Barrett, L.F. \& Bar, M. (2009). See it with feeling: affective predictions during object perception. Philosophical Transactions of the Royal Society B, 364, pp.1325-1334.

Barthes, R. (1989). The reality effect. In Hale, D.J. (Ed.) \& Howard, R. (Trans.), The Novel: an anthology of criticism and theory 1900-2000. Oxford: Blackwell. 
Barsalou, L. (2008). Grounded cognition. Annual Review of Psychology, 59, pp.617645.

Bauman, R. (1986). "I go into more detail now, to be sure"; narrative variation and the shifting contexts of traditional storytelling. In Story, Performance and Event. Cambridge: Cambridge University Press. Chapter five.

Bemis, D.K. \& Pylkkänen, L. (2013). Basic linguistic composition recruits the left anterior temporal lobe and left angular gyrus during both listening and reading. Cerebral Cortex, 23 (8), pp.1859- 1873.

Berlyne, D. 1960. Conflict, Arousal and Curiosity. New York: McGraw-Hill.

Berlyne, D. 1971. Aesthetics and Psychobiology. New York: Appleton-CenturyCrofts.

Blumenthal, A. (1967). Prompted recall of sentences. Journal of Verbal Learning and Verbal Behavior, 6, pp.674-675.

Boden, M. (2004) [1990], The Creative Mind: myths and mechanisms. Routledge, London.

Bouvet, R. \& Bonnefon, J. (2015). Non-reflective thinkers are predisposed to attribute supernatural causation to uncanny experiences. Personality and Social Psychology Bulletin, 4, pp. 955-961.

Bransford, J.D., Barclay, J.R. \& Franks, J. J. (1972). Sentence memory: a constructive versus interpretive approach. Cognitive Psychology, 3, pp.193-209.

Brewer, W. F. \& Lichtenstein, E. H. 1982. Stories are to entertain: a structural-affect theory of stories. Journal of Pragmatics, $6473-486$.

Chow, H.M., Mar, R.A., Xu, Y., Liu, S., Wagage, S. \& Braun, A.R. (2014). Embodied comprehension of stories: interactions between language regions and modality-specific neural systems. Journal of Cognitive Neuroscience, 26, pp.279-295.

Churchland, P.M. (2012). Plato's Camera: how the physical brain captures a landscape of abstract universals. Cambridge Mass: MIT Press.

Clark, A. (2013). Expecting the world: perception, prediction and the origins of human knowledge. Journal of Philosophy, 110, pp. 469-496.

Clark, A. (2016). Surfing Uncertainty: prediction, action and the embodied mind. Oxford University Press, Oxford.

Clayton, N.S. \& Dickinson, A. (1998). Episodic-like memory during cache recovery by scrub jays. Nature, 395 , pp. 272-278. 
Clayton, N.S. \& Dickinson, A. (1999). Scrub jays (Aphelocoma coerulescens) remember when as well as where and what food item they cached. Journal of Comparative Psychology, 113, pp. 403-416.

Csikszentmihalyi, M. (1990). Flow: the psychology of optimal performance. Cambridge: Cambridge University Press.

Cutting, J., Brunick, K., DeLong, J., Iricinschi, C. \& Candan, A. 2011. Quicker, faster, darker: changes in Hollywood film over 75 years. i-Perception, 2, pp.569576.

Delong, K.A., Urbach, T.P. \& Kutas, M. (2005). Probabilistic word pre-activation during language comprehension inferred from electrical brain activity. Nature Neuroscience, 8, pp. 1117-1121.

Egner, T, \& Summerfield, C. (2013). Grounding predictive coding models in empirical neuroscience research. Comments on Clark, A. (2013). Whatever next? Predictive brains, situated agents, and the future of cognitive science. Behavioral and Brain Sciences, 36. pp.210-211.

Elman, J.L. (1990). Finding structure in time. Cognitive Science, 14, pp. 179-211.

Ennemoser, M. \& Schneider, W. 2007. Relations of television viewing and reading: findings from a 4-year longitudinal study. Journal of Educational Psychology, 99 (2), $349-368$.

Fischer, M. H., and Shaki, S. (2014). Spatial associations in numerical cognitionfrom single digits to arithmetic. Quarterly Journal of Experimental Psychology, 67, pp. 1461-1483.

Fiske, S., Dupree, C., Gandalf, N. \& Swencionis, J. (2016). Status, power, and intergroup relations: the personal is the societal. Current Opinion in Psychology, 11, pp. $44-48$.

Gerrans, P. (2014). Pathologies of hyperfamiliarity in dreams, delusions and déjà vu. Frontiers in Psychology, 5 (article 97). 1 - 10.

Gerrig, R. (1993). Experiencing Narrative Worlds. New Haven, CT: Yale University Press.

Gerrig, R.J. \& O’Brien, E.J. 2005. The scope of memory-based processing. Discourse Processes, 39, pp.225 - 242.

Gibson, J. (1966). The Ecological Approach to Visual Perception. Houghton Mifflin.

Glenberg, A., Meyer, M. \& Lindem, K. (1987). Mental models contribute to foregrounding during text comprehension. Journal of Memory and Language, 26, pp.69-83.

Glenburg, A.M. \& Kaschak, M.P. (2002). Grounding language in action. Psychonomic Bulletin and Review, 9, pp.558-565. 
Graesser, A., Singer, M. \& Trabasso, T. (1994). Constructing inferences during narrative text comprehension. Psychological Review, 101, pp.371-395.

Graesser, A., Olde, B. \& Klettke, B. (2002). How does the mind construct and represent stories? In M. Green, J. Strange \& T. Brock, eds. Narrative Impact: social and cognitive foundations. Mahwah, NJ: Erlbaum. pp.229-262.

Green, M. \& Brock, T. (2002). In the mind's eye: imagery and transportation into narrative worlds. In M. Green, J. Strange \& T. Brock, eds. Narrative Impact: social and cognitive foundations. Mahwah, NJ: Erlbaum. pp.315 - 341.

Griffith, G. (2012). Merlin. In Cartlidge, N. (Ed.), Heroes and Anti-Heroes in Medieval Romance. Cambridge: D.S. Brewer. pp. 99-114.

Grimm, F. \& Grimm, W. (1973). In L Segal, L. \& Jarrell, R. (Trans.), The Juniper Tree and other tales from Grimm. London: Bodley Head.

Grimes, J. (1996). On the failure to detect changes in scenes across saccades. In Atkins, K.A. (Ed.), Perception, vol.5. Oxford: Oxford University Press.

Hauk, O., Davis, M.H., Kherif, F. \& Pulvermüller, F. (2008). Imagery or meaning? Evidence for a semantic origin of category-specific brain activity in metabolic imaging. European Journal of Neuroscience, 27, pp. 1856-66.

Hasson, U., Landesman, O., Knappmeyer, B. Vallines, I., Rubin, N. \& Heeger D. 2008. Neurocinematics: the neuroscience of film. Projections, 2 (1), pp. $1-26$.

Heider, F. 1944. Social perception and phenomenal causality. Psychological Review, 51 (6), pp.358-374.

Henderson, J.M. (2003). Human gaze control in real-world scene perception. Trends in Cognitive Sciences, 7, pp.498-504.

Hinton, G.E., Osindero, S., \& Teh, Y. (2006). A fast learning algorithm for deep belief nets. Neural Computation, 18, pp.1527-1554.

Hinton, G.E., \& Salakhutdinov, R.R. (2006). Reducing the dimensionality of data with neural networks. Science, 313, pp.504-507.

Hobson, J.A. \& K.J. Friston, K.J. (2012). Waking and dreaming consciousness: neurobiological and functional considerations. Progress in Neurobiology, 98, pp. 8298 .

Jajdelska, E. (2016). Being there yet not there: why don't embodied responses to literary texts jar with one another? Journal of Literary Semantics, 45 (1), pp. 1 - 20.

Johnson-Laird, P.N. (1983). Mental Models: towards a cognitive science of language, inference, and consciousness. Cambridge, Mass: Harvard University Press. 
Jordan, M.I. (1986). An introduction to linear algebra in parallel distributed processing. In Rumelhart, D.E. \& McClelland, J.L. (Eds.), Parallel Distributed Processing, 2 vols., Cambridge, Mass: MIT Press. pp. 365-422.

Kamide, Y., Altmann, G.T.M. \& S. L. Haywood. (2003). The time-course of prediction in incremental sentence processing: evidence from anticipatory eye movements. Journal of Memory and Language, 49, pp. 133-156.

Kamide, Y., Scheepers, C. \& Altmann, G.T.M. (2003). Integration of syntactic and semantic information in predictive processing: cross-linguistic evidence from German and English. Journal of Psycholinguistic Research, 32, pp. 37-55.

Katz, J.J. \& Postal, P.M. (1964). An Integrated Theory of Linguistic Descriptions. Cambridge, Mass: MIT Press.

Keen, S. (2007). Empathy and the Novel. Oxford: Oxford University Press.

Kersten, D., Mamassian, P. \& Knill, D. (1997). Moving cast shadows induce apparent motion in depth. Perception, 26 (2), pp.171-192.

Kibbe, M., Kreisky, M. \& Weisberg, D. (2017). Young children distinguish between different unrealistic fictional genres. Psychology of Aesthetics, Creativity \& the Arts, 11 .

Kiefer, M. \& Pulvermüller, F. 2012. Conceptual representations in mind and brain: theoretical developments, current evidence and future directions. Cortex, 48, pp.805825 .

Kintsch, W. (1977). On comprehending stories. In M.A. Just \& P.A. Carpenter (Eds.), Cognitive Processes in Comprehension. pp.33 - 62. New York: Psychology Press.

Kintsch, W. \& van Dijk, T. (1978). Cognitive psychology and discourse. Recalling and summarising stories. In W.U. Dressler, W.U. (Ed.), Current Trends in Text Linguistics. Berlin/New York: De Gruyter. Pp.61-80.

Kirchhoff, M.D. 2018. Predictive processing, perceiving and imagining: Is to perceive to imagine, or something close to it? Philos Stud [CHECK FULL NAME], 175, 751 767.

Knoblich, G., Seigerschmidt, E., Flach, R. \& Prinz, W. (2002). Authorship effects in the prediction of handwriting strokes: evidence for action simulation during action perception, Quarterly Journal of Experimental Psychology, section A, 55 (3), pp.1027-1046.

Knoeferle, P., Crocker, M.W., Scheepers, C. \& Pickering, M.J. (2005). The influence of the immediate visual context on incremental thematic role-assignment: evidence from eye-movements in depicted events. Cognition, 95, pp. 95-127.

Kuperberg, G. \& Jaeger, F. (2016). What do we mean by prediction in language comprehension? Language, Cognition and Neuroscience, 31 (1), pp.32 - 59. 
Lord, A. 2000. The Singer of Tales. Cambridge, Mass: Harvard University Press. Loschky, L., Larson, A., Magliano, J., \& Smith, T. 2015. What would Jaws do? The Tyranny of film and the relationship between gaze and higher-level narrative film comprehension. PLOS ONE. 10 (11). E0142474.

Lwin, S.M. (2010). Capturing the dynamics of narrative development in an oral storytelling performance: a multimodal perspective. Language and Literature, 19, pp.357-377.

Malinowski, B. (1926). Myth in Primitive Psychology, London: Keegan Paul.

Mandler, J.M. \& Johnson, N.S. (1977). Remembrance of things parsed: story structure and recall. Cognitive Psychology, 9, pp.111-151.

Mar, R. \& Oatley, K. (2008). The function of fiction is the abstraction and simulation of social experience. Perspectives on Psychological Science, 3 (3), pp.173 - 192.

McKoon, G. \& Ratcliff, R. (1998). Memory-based language processing: psycholinguistic research in the 1990s. Annual Review of Psychology, 49, pp.25- 42.

McNamara, D. \& Magliano, J. (2009). Towards a comprehensive model of comprehension. In The Psychology of Learning and Motivation, Vol. 51, ed. Brian Ross. Burlington: Academic Press. 297 - 384.

Meyer, B.J. (1975). The Organization of Prose and its Effects on Memory. New York: North Holland Publishing Company.

Miall, D. \& Kuiken, D. 1994. Foregrounding, defamiliarization, and affect: response to literary stories. Poetics, 22, pp.389- 407.

Miall, D. \& Kuiken, D. 1999. What is literariness? Three components of literary reading. Discourse Processes, 28, pp.121-138.

Mitchell, D. \& Cusack, R. (2016). Semantic and emotional content of imagined representations in human occipitotemporal cortex. Nature Scientific Reports, 6, article 20232.

Mordvintsev, A., Olah, C. \& Tyka, M. (2015). Inceptionism: going deeper into neural networks. url: https:/research.googleblog.com/2015/06/inceptionism-going-deeperinto-neural.html. Consulted 12 July 2017.

Morera, Y., León, Escudero, I. \& Vega, M. (2017). Do causal and concessive connectives guide emotional expectancies in comprehension? A double-task paradigm using emotional icons. Discourse Processes, 54 (8), pp.583 - 598.

Morrow, D.G., Greenspan S.L. \& G.H. Bower. (1987). Accessibility and situation models in narrative comprehension. Journal of Memory and Language, 26. pp.165187. 
Muijselaar, M.M.L. \& de Jong, P. (2015). The effects of updating ability and knowledge of reading strategies on reading comprehension. Learning and Individual Differences, 43, pp.111-117.

Mulhall, S. (2007). The mortality of the soul: Bernard Williams's character(s). In A. Crary (Ed.), Wittgenstein and the Moral Life: essays in honor of Cora Diamond Cambridge, Mass: MIT Press. pp.355-380.

Mullally, S., Intraug, H. \& Maguire, E. (2012). Attenuated boundary extension produces a paradoxical memory advantage in amnesic patients. Current Biology, 22. 261-268.

Newtson, D. (1973). Attribution and the unit of perception of ongoing behaviour. Journal of Personality and Social Psychology, 28, pp.28 - 38.

Norenzayan, A., Atran, S., Faulkner, J. \& Schaller, M. 2006. Memory and mystery: the cultural selection of minimally counterintuitive concepts. Cognitive Science. 30. 531-553.

Otten, M. \& van Berkum, Jos. (2008). Discourse-based word anticipation during language processing: prediction of priming? Discourse Processes, 45, pp. 464-496.

Overy, K. \& Molnar-Szakacs, (2009). Being together in time: musical experience and the mirror neuron sysem. Music Perception, 26, pp.489-504.

Propp, V. 2010. Morphology of the Folk Tale, trans. Laurence Scott, Austin: University of Texas Press.

Rapp, D.N., Gerrig, R.J. \& Prentice, D.A. (2001). Readers' trait-based models of characters in narrative. Journal of Memory and Language, 45, pp.737-750.

Reddy, L., Tsuchlya, N. \& Serre, T. (2010). Reading the mind's eye: decoding category information during mental imagery. Neuroimage, 50, pp. 818-825.

Rumelhart, D.E. (1975). Notes on a schema for stories. In Bobrow, D.G. \& Collins, A. (Eds.), Representation and Understanding: studies in cognitive science. New York: Academic Press. pp.211-236.

Rumelhart, D.E. (1977). Understanding and summarising brief stories. In LaBerge, D. \& Samuels, S.J. (Eds.), Basic Processes in Reading: perception and comprehension. Hillsdale, New York: Lawrence Erlbaum.

Rumelhart, D.E. and McClelland, J.L. (Eds.). (1986). Parallel Distributed Processing. 2 vols. Cambridge, Mass: MIT Press.

Sachs, J. (1967). Recognition memory for syntactic and semantic aspects of connected discourse. Perception and Psychophysics, 2, pp.437-442. 
Sanford, A. \& Emmott, C. (2012) Mind, Brain and Narrative. Cambridge: Cambridge University Press.

Seth, A.K. (2014). A predictive processing theory of sensorimotor contingences: explaining the puzzle of perceptual presence and its absence in synesethesia. Cognitive Neuroscience, 5 (2), pp.97 - 118.

Smith, T. \& Henderson, J. M. (2008). Edit blindness: the relationship between attention and global change blindness in dynamic scenes. Journal of Eye Movement Research, 2, pp.1-17.

Speer, N.J., Zacks, J. \& Reynolds, J.R. (2007). Human brain activity time-locked to narrative event boundaries. Psychological Science, 18, pp. 449-455.

Speer, N.K., Reynolds, J.R., Swallow, K.M. \& Zacks, J.M. (2009). Reading stories activates neural representations of visual and motor experiences. Psychological Science, 20, pp. 989-999.

Spivey, M. (2007). The Continuity of Mind, Oxford University Press, Oxford.

Stanovich, K. \& West, R. (2000). Individual differences in reasoning: implications for the rationality debate. Behavioral and Brain Sciences, 23, pp.645-665.

Stein, N.L. \& Glenn, C.G. (1979). An analysis of story comprehension in elementary school children. In Freedle, R.O. (Ed.), New Directions in Discourse Processing. Norwood, N.J: Ablex. pp.53-120.

Stein, B., Huneycutt, W. \& Meredith, M. 1988. Neurons and behaviour: the same rules of multisensory integration apply. Brain Research, 448, pp.355 - 358.

Sternberg, M. (1978). Expositional Modes and Temporal Ordering in Fiction. Baltimore, MD: Johns Hopkins University Press.

Sternberg, M. (2003). Universals of narrative and their cognitivist fortunes (I). Poetics Today, 24, $297-395$.

Strong, C.J. 1998. The Strong Narrative Assessment Procedure. Eau Claire, WI: Thinking Publications.

Suddendorf, T. \& Busby, J. (2003) Mental time travel in animals? Trends in Cognitive Sciences, 7, pp. 391-396.

Tan, E.S. (1994). Story processing as an emotion episode. In H. Van Oostendorp \& R.A. Zwaan, eds. Naturalistic Text Comprehension. Norwood, N.J.: Ablex, $167-$ 188.

Tehrani, J.J. (2003). The phylogeny of Little Red Riding Hood. Plos One, 8, pp. 1-11.

Thompson, S. (1946). The Folktale. New York: Holt, Rinehart and Winston. 
Thompson, S. 1955-1958. Motif-Index of Folk Literature. 6 vols. Bloomington: Indiana University Press.

Thorndyke, P.W. (1977). Cognitive structures in comprehension and memory of narrative discourse. Cognitive Psychology, 9, pp.77-110.

Trabasso, T. \& Wiley, J. (2005). Goal plans of actions and inferences during comprehension of narratives. Discourse Processes, 39, pp.129- 164.

Turi, J. (1931). Turi's Book of Lappland. Ed. and translated into Danish by E.D. Hatt, translated from Danish by E.G. Nash, Jonathan Cape, London and Toronto.

Van Berkum, J.J.A., Brown, C.M., Zwitserlood, P., Kooijman, V. \& Hagoort, P. (2005). Anticipating upcoming words in discourse: evidence from ERP's and reading times. Journal of Experimental Psychology: learning, memory, and cognition, 31, pp. 443-467.

Van Dijk, T.A. (1977). Semantic macro-structures and knowledge frames in discourse comprehension. In M.A. Just \& P.A. Carpenter (Eds.), Cognitive Processes in Comprehension (pp.3-32).

Van Dijk, T.A. \& Kintsch, W. (1983). Strategies in Discourse Comprehension, New York: Academic Press.

Wacongne, C., Changeux, J.-P. \& Dehaene, S. (2012). A neuronal model of predictive coding accounting for the mismatch negativity. Journal of Neuroscience, 32, 36653678 .

Ward, J., Thompson-Lake, D., Ely, R. \& Kaminski, F. (2008). Synaesthesia, creativity and art: What is the link?. British Journal of Psychology, 99, pp. 127-141.

Westerlund, M., Kastner, I., Al Kaabi, M., Pylkkänen. (2015). The LATL as locus of composition: MEG evidence from English and Arabic. Brain \& Language, 141, pp.124-134.

Whitehead, W. (1999). Supporting Language and Literacy Development in the Early Years. Maidenhead: Open University Press.

Wicha, N.Y., Moreno, E.M. \& Kutas, M. (2004). Anticipating words and their gender: an event-related brain potential study of semantic integration, gender expectancy, and gender agreement in Spanish sentence reading. Journal of Cognitive Neuroscience, 16, pp. 1272-1288.

Zacks, J., Tversky, B. \& Iyer, G. (2001). Perceiving, remembering and communicating structure in events. Journal of Experimental Psychology: General, 130 , pp. $29-58$.

Zacks, J.M., Speer, N.K., Swallow, K.M., Braver, T.S. and Reynolds, J. R. (2007). Event structure in perception and conception. Psychological Bulletin, 127, pp.3-21. 
Zacks, J.M., Speer, N.K. \& Reynolds, J.R. (2009). Segmentation in reading and film comprehension. Journal of Experimental Psychology: general, 138, pp.307-327.

Zacks, J.M. (2015). Flicker: your brain on movies. Oxford: Oxford University Press.

Zwaan, R., Langston, M.C. \& Graesser, A.C. (1995). The construction of situation models in narrative comprehension: an event-indexing model. Psychological Science, 6, pp. 292-297.

Zwaan, R., Magliano, J.P. and Graesser, A.C. (1995). Dimensions of situation model construction in narrative comprehension. Journal of Experimental Psychology:

learning, memory, and cognition, 21, pp.386-397.

Zwaan, R.A. \& Radvansky, G.A. (1998). Situation models in language comprehension and memory. Psychological Bulletin, 123, pp. 162-185.

Zwaan, R.A. (2009). Embodied cognition, perceptual symbols, and situation models, Discourse Processes, 28, pp. 81-88. 


\section{TO REVIEWERS:}

This is a revised submission of a manuscript that previously received a decision by the editors of Philosophical Psychology.

If you are viewing this as a PDF, please note that this PDF contains two versions of the manuscript: one without tracked changes followed by one with tracked changes, followed by the author's response to issues raised by the reviewers.

If you are viewing this as HTML, please find the version with tracked changes and the author's response to reviewers from the list of files in the upper-left of the window. 
THE FLOW OF NARRATIVE IN THE MIND UNMOORED: AN ACCOUNT OF NARRATIVE PROCESSING

Philosophical Psychology

Elspeth Jajdelska

School of Humanities, University of Strathclyde, Glasgow, UK. elspeth.jajdelska@strath.ac.uk

$\underline{\text { ACKNOWLEDGEMENTS }}$

My thanks to Andy Clark for conversation and comments on earlier versions of this article, to Nigel Fabb and Elizabeth Finnigan for comments, and to the anonymous reviewers at Philosophical Psychology.

\begin{abstract}
Verbal narratives provide incomplete information and can be very long. Yet readers and hearers often effortlessly fill in the gaps, and make connections across long stretches of text, sometimes even finding this immersive. How is this done? In the last few decades, event-indexing situation modelling and complementary accounts of narrative emotion have suggested answers. DBHut despite this progress, comparisons between real life perception and narrative experience might underplay-they way narrative processing modifies our world model, and the role of those emotions that do not relate to charactersboth changes to our model of the world in narrative processing,
\end{abstract}


and the role of reader emotions which are unrelated to characters. I reframe narrative experience in predictive processing and neural networks, capturing continuity between fiction, perception and states like dreaming and imagination, enabled bythrough the flexible instantiation of concepts. In this framework, narrative experience is more clearly revealed as a creative experience that can share some of the phenomenology of dreams.

\section{KEYWORDS}

stories; narrative; situation model; event indexing; emotion; neural nerk; predictive processing; creativity.

\section{$\underline{\text { Introduction }}$}

The tale of two men who went to look for Old Man Furry.

And they were strong, both of them, and the one had killed many bears, but the other had not hunted bears before, and he was afraid, and untrained. And when they found Old Man Furry, he was so angry that he rushed upon them in an instant, and they jumped behind a big pine tree (Turi, 1931, p.128).

How might the Sami audience listening to this story have known why the men jumped behind a tree? How did they remember, as the story continued, that only one was an experienced hunter? And why might they have kept listening? These questions can be framed as: how do we infer missing information from a narrative text? how do we connect information across the text so as to experience it as coherent? and why can stories be immersive, rendering us indifferent to our environments and usual trains of thought? 
To answer these questions, I begin with a summary of event-indexed processing leading to situation models, currently the dominant account of verbal narrative processing. I suggest that despite many strengths, this account of narrative processing is constrained by a separation between inferred information and emotion. I suggest a way to redescribe narrative processing using predictive processing ( $\mathrm{PP})$ in a high dimensional vector space, allowing a holistic 'single computation' of all aspects of narrative experience (Clark 2016, 296). This approach recognises the existence of the situation model (SM) as one level of memory representation arising from narrative processing. Skeletal event sequences identified by anthropologists off oral narrative, used after the event to retell/adapt stories, for example, bear some resemblance toas SMs (Bauman 1986, chapter 5; Aarne and Thompson, 1928). It is not the only level, but I argue that the aspects of narrative processing relating to other levels of representation must be recruited to explain the SM level; that the inferences leading to an SM must draw on the full range of narrative experience The article offers a holistic account of narrative processing looking at the dynamic interactions of emotion and inference and the ways they depart from real world perception. Seen like this, narrative processing can not only simulate the world, but imaginatively remodel it. $\underline{\text { Situation models and event indexing }}$

In the 1960s researchers on narrative often assumed modular models of language processing, representing the text's linguistic form rather than directly representing content (Katz \& Postal, 1964; Blumenthal, 1967; Sachs, 1967). Bransford and colleagues challenged these assumptions in the early 1970s, showing how spatial representations are needed to process sentences like this one: "Three turtles rested on a floating log and a turtle swam beneath them". They concluded that sentences should not be "viewed as linguistic objects to be remembered" but as 
"information which [people] can use to construct semantic descriptions of situations" (Bransford, Barclay \& Franks, 1972, p.194).

These findings were followed in the 1980s by Johnson-Laird's work (1983) on mental models and van Dijk and Kintsch's (1983) on situation models. Johnson-Laird argued that "human beings understand the world by constructing working models of it in their minds," models which "are simpler than the entities they represent" (JohnsonLaird, 1983, p.10). Van Dijk and Kintsch proposed a distinction between "the text representation proper" and "a model that the reader or hearer constructs about the relevant information for the adequate comprehension of the text" (Van Dijk \& Kintsch 1983, p.337). This combined body of work suggested that verbal narrative processing, using spatial representations, enables the creation of SMs (Morrow, Greenspan \& Bower, 1987). This does not commit SM advocates to the claim that SMs are the only level of memory representation produced by narrative processing, although, as Mar \& Oatley observe (2008, p.174), SMs can explain memory for text narrative at both automatic (Gerrig \& O’Brien, 2005; McKoon \& Ratcliff, 1998) and conscious, intentional levels (Graesser et al, 1994), and support inferences arising not just from spatial relationships, but also fromef characters' short and long term goals (Glenberg et al, 1987; Trabasso \& Wiley 2005).

Narrative text was also increasingly analysed in hierarchically organised chunks. In Van Dijk and Kintsch's "macro structure theory,” for example, plot exists at a macro level and has a rule governed relationship to micro episodes (van Dijk, 1977; Kintsch, 1977; Kintsch \& van Dijk, 1978). Emerging "story grammar" theories also involved hierarchical organisation around characters and their goals (Rumelhart 1975, 1977; Meyer, 1975; Thorndyke, 1977; Mandler \& Johnson, 1977; Stein \& Glenn, 1979). 
These hierarchical organisations of narrative resembled new accounts of event perception. Events are bounded, hierarchically nested, segments of time. "Opening a door," for example, can be one event within the higher order event of "arriving at a party” (Newtson, 1973; Zacks \& Tversky, 2001). An event boundary is perceived when there is simultaneous change across a set of key dimensions (Zacks et al, 2007). The "event indexing model" provided an explanation of how narrative processing could lead to SMs (Zwaan, Langston \& Graesser, 1995; Zwaan, Magliano \& Graesser, 1995). In what follows, I suggest that replacing this limited number of commonsense dimensions with a high dimensional vector space can improve our understanding of the relationship between event segmentation, the creation of SMs and narrative experience more broadly.

The existing dimensions of event change indexed by readers are: which character is this?; change in characters' goals; new information about causation; change in location; change in the time of events narrated; and change in characters' interactions with objects (Zwaan \& Radvansky, 1998; Zacks, Speer \& Reynolds, 2009). This model is used by most researchers working on narrative processing today (for examples, see Zacks, 2015; Chow et al, 2014; Muijselaar, 2015). The production of SMs can provide readers and hearers of verbal narrative with a global sense of a story, by organising information around the key dimensions (Sanford \& Emmott 2013, pp.37 - 38). The production of SMs also relates to narrative inferences: the situation builds in knowledge of the world, which is not always explicit in the text. The process of SM construction has been used to explain immersion in verbal narrative through embodied language processing drawing on behavioural and neuroimaging work in embodied language processing such as that of Reddy (2010), Hauk (2008), Barsalou (2008), Glenburg \& Kaschak (2002), Speer et al (2007) and 
others (Zwaan, 1999). These approaches to narrative processing are- compatible with, and sometimes supported by, accounts of emotion and empathy in response to film and verbal narrative by Tan, Sanford \& Emmott and others (Tan 1994; Sanford \& Emmott, 2013, 44, pp.191 - 232).

By moving from modular models of verbatim text representation, event indexing and situation modelling have revealed shared elements in narrative processing across media, including film (Zacks, 2015; Speer, Zacks and Reynolds, 2007; Magliano, 2012), and a comparative framework for variations in narrative processing between individuals (Kurby, 2011; Bohn-Gettler, 2011). They make clear predictions, for example that processing at event boundaries in the text will be slower (Zacks, Speer \& Reynolds, 2000). By recruiting embodied language processing to verbal narrative, they share in a broader move towards embodiment in the cognitive sciences (Clark, 1997; Clark, 2016, pp. 109-240).

These gains have been won by recruiting the resources of everyday perception (Zacks, 2015). However, the current account of the processing behind SMs may neglect the status of verbal narrative as an artefact, a product of human behaviour, whose processing may be comparable to cognition of, say, music or handwriting (Knoblich et al, 2002; Overy \& Molnar-Szakacs, 2009). In what follows, I exploit the flexible frameworks of PP and neural networks to explore differences between the narrative processing that produces SMs, and everyday perception.

I illustrate my account with the case of a child listening to a fairy tale. Fairy tales come closer to a universal narrative experience than the texts used in many experiments; they are found in diverse cultures and periods, and are accessible to very young hearers with a minimum of prior skill in narrative comprehension (Tehrani, 2003, pp.1-11; Aarne and Thompson, 1928). 


\section{Listening to The Juniper Tree}

The Juniper Tree was collected and edited by the Grimm brothers in the early nineteenth century, and has several cognates in other cultures (Grimms 1973, 314332; Aarne and Thompson 1928, tale type 720). Very young children, from a wide range of cultures, frequently become immersed in stories like this, as the tales' persistence across time and place, and with young audiences, suggests (Tehrani, 2003, pp.1-11; Whitehead 1999, pp.104-107). I analyse the opening of The Juniper Tree in the light of existing approaches to the processing that leads to SMs and discuss some problems this analysis identifies:
It is a long time ago now, as much as two thousand years maybe, that there was a rich man and he had a wife and she was beautiful and good, and they loved each other very much but they had no children even though they wanted some so much, the wife prayed and prayed for one both day and night, and still they did not and they did not get one. In front of their house was a garden and in the garden stood a juniper tree. Once, in wintertime, the woman stood under the tree and peeled herself an apple, and as she was peeling the apple she cut her finger and the blood fell onto the snow. "Ah," said the woman and sighed a deep sigh, and she looked at the blood before her and her heart ached. "If I only had a child as red as blood and as white as snow." And as she said it, it made her feel very happy, as if it was really going to happen (Grimms, 1973, pp.314-315).

There are several examples here of the five dimensions of change (time, space, causation, motivation and protagonist; Zwaan \& Radvansky 1998): longing for a child and peeling an apple (goals); and "in winter" or "under the tree" (changes in time and 
location). Situation modelling of verbal narrative involves an embodied approach to modelling space, and event-indexing in narrative involves simulating embodied experiences of real life environments (Zacks, 2015, 449). These embodied experiences can be seen as a source of emotion, either intrinsic to creating the SM (Zwaan 2009), or complementary to it (Sanford \& Emmott, 2012, pp.191 - 232). The potential for embodied responses to the text through actions - peeling an apple, cutting a finger, looking at blood on snow - can help, then, to explain immersion if it occurs.

But here also lies a problem. If an embodied response to a text about cutting a finger and bleeding generates emotion, the emotion ought to be negative, even distressing, particularly for child hearers. The character's happiness might then be experienced as incoherent. Yet the success of this tale, particularly with children, included repeatedly in editions of Grimms' tales over 200 years, suggests that it is not.

Generic experience of fairy tales might help hearers to bridge the gap between real life experience and narrative. Genre knowledge could certainly prepare the child hearer for departures from real world experience, such as minimally counterintuitive concepts, like the talking bird who appears later in the tale (Norenzayan 2006; Thompson 1955-1958). But generic knowledge cannot filter "happiness" from the range of relevant potential responses to injuring one's finger; a generic example like Sleeping Beauty could even make this harder (Kibbe et al, 2017).

An alternative solution to explain how processing produces the relevant information for an SM might be to distinguish reader emotion from the emotion in response to character alone. Moves in this direction have been made by Tan (1994) and Sanford \& Emmott (2013). Tan attributes to readers/viewers not, or not just, the 
simulated emotions of characters, but the emotions of an impotent witness of the characters, and argues that these emotions enable, rather than just arising from, predictive inferences (Tan 1994, p.184). Sanford and Emmott suggest that "scenario mapping" and embodied responses allow the emotions of characters to be "built into" readers' "mental representations". These lead to reader emotions, modulated by approval, liking or closeness to the characters into macro narrative structures of curiosity, surprise and suspense, which can generate arousal jags and boosts (pp.196, 207; drawing on Berlyne 1960, 1971; Brewer and Lichtenstein, 1982; Sternberg 1978, 2003).

On their own, however, these accounts cannot solve the problem with The Juniper Tree. Children are frequently impotent witnesses of scenes involving adults, and it is not clear that in this case the child's response to seeing an adult woman cut her finger would enable her to predict the woman's happiness. This passage may create distance rather than Sanford and Emmott's closeness - the characters exist in an unspecified place and a distant and unspecified time. They have morally attractive characteristics - they love one another, they would love a child - but they perform no actions in this passage thatwhich are open to moral evaluation either way. It would be hard to say that a four-year-old child has enough here to generate liking, dislike or (dis)approval. This would be hard to settle without empirical investigation, but it is at least questionable that emotions arising from closeness, approval and liking, in turn leading to hopes and fears, and from there to arousal jags and boosts, can explain why very young children-ean-are not puzzled by the woman's response to a cut finger.

A holistic account of the hearer's emotional responses to narrative, however, can build on Tan's alertness to the role of reader/hearer impotence in narrative experience, and of the distinction between reader emotion and character emotion. In 
perception, we act on the environment to deepen our understanding of it, if only through eye saccades (Grimes, 1996; Smith and Henderson, 2008; Henderson, 2003). In narrative experience, however, we are unmoored from our immediate environment; the hearer of a narrative cannot act on the stimulus to derive greater sensual information about the scene depicted. Both perception and narrative may engage the same machinery of predicting incoming signals, as I discuss below (Clark 2016;

Gerrans 2014). But the concepts instantiated by language cannot always be interrogated in the same sensory depth as those arising from perception and action embedded in an environment. Instead, they may be experienced in relationship to one another, isolated from a shared environment. Even the eye saccades crucial to film comprehension can be highly determined by lighting, camera angle, montage etc, and the film is not fully available for ecological interrogation through the viewer's bodily location and action (Cutting et al 2011; Hasson et al 2008; Loschky et al 2015; Gibson 1979).

In the first part of the passage from The Juniper Tree, the hearer encounters the concepts of a rich man, a good and beautiful wife, the absence of a child, longing for a child and praying for a child. The hearer's passivity, her inability to act on the stimulus, means that none of this information can be further probed. The man and the wife may give rise to embodied neural effects in relevant sensory and motor areas, but these are not instantiated in relation to the child's perceiving body. Encountering a "rich man" face to face, for example, would instantiate a power relationship with a child, with embodied consequences (Fiske et al, 2016). Encountering the concept through language, however, potentially neutralises such effects and frees the set of concepts to interact in novel ways. The "feature tuning" of mental images in response to nouns (such as "man" and "wife") can vary considerably with verbal context 
(Mitchell \& Cusack, 2016, pp. 4 - 7). "Man" and "wife”, dis-embedded from a rich scene, might mutually influence each other's instantiations. "Rich" in conjunction with "beautiful" might give prominence to the beautiful belongings that wealth can buy, rather than, say, the cruel behaviour that wealth can sometimes enable.

The interactions of this small set of concepts then ("man", "wife", "rich", "beautiful"), when experienced passively (in the sense that the body cannot glean additional sensory information), in isolation from an environment, and unmoored from a perceiving body, may subtly modify the hearer's statistical model of the world's hierarchy of proximal and distal causes and effects (Clark, 2016; Kirchhoff 2018). For example, the conjunction of "good", "rich", "loving" and "beautiful" with "lack" and "longing" may point to a rightly ordered world that has somehow gone wrong; the blessed can also be unblessed. Similarly, the imagery of blood on snow can be separated from the embodied experience of the cut, so that the blood and snow - again, pushed together through isolation from a perceiving body in a richer environment - can be instantiated through contrasts of colour, temperature and texture. As their other features drop out, the aesthetic effect of this combination may dominate the potential for distress in a child's simulation of cutting herself and watching herself bleed, recalling Miall and Kuiken's distinction between "narrative emotions" (relating to characters) and "aesthetic emotions" (Miall \& Kuiken, 1994, 1999). The isolation, and then conjunction, of juniper tree, snow, blood, apple, aesthetic thrill, and a sudden transition from longing to joy then become causally implicated in the subsequent conception of a child.

This analysis shows the kind of thing that could happen, rather than what must happen, but it is enough to raise a doubt that the existing account of event segmentation, leading to SMs, using a fixed set of commonsense dimensions, 
alongside- theories of emotional response to characters, can explain this and similar narrative inferences which are needed for the SM. In the next section I explore the mechanisms by which this hearer might be immersed in narrative through the unfolding of a subtly unfamiliar trajectory; a succession of points in a multidimensional space.

\section{$\underline{\text { Stratified versus holistic organisation of narrative information }}$}

Zwaan and Radvansky predict that there may turn out to be more than five narrative dimensions involved in the production of SMs (p.167; see Rapp, 2001 for a proposed addition). But there is currently no suggestion that the number extends beyond common sense concepts such as "location" or "goal". If "Bill is very tall" turns out to be irrelevant to subsequent situations, it is "relegated" and excluded from | "subsequent situation models".- If the reader later finds that "Bill could see over everyone's head", the information can be retrieved and "stored directly with the token in the model" (Zwaan and Radvansky, 1998, pp.11, 17, 19 - 20).

Zwaan and Radvansky are not proposing, then, a division of information into "modelled" and "discarded". But their account does imply that incoming information can and should be identified as having greater or lesser importance for the model. If all the incoming information could immediately be incorporated in the model without compromising it, there would be no need to monitor the dimensions. The power of an SM is not just, as Zwaan and Radvansky correctly point out (pp.162-163), that it is more efficient than storing representations of verbatim text, but that it is more efficient than treating all of the information provided by verbatim text as equally important. While other levels of narrative memory and representation may operate outside an informational hierarchy of this kind, it would seem to be essential for event segmentation and the formation of SMs. 
I suggest, however, that in the case of The Juniper Tree, dividing the textual information in this way can only be done by sacrificing, among other things, the contribution of emotion to narrative inference and coherence. Look again at the quotation above, from, "In front of their house...". To update her SM as she hears this passage, the child hearer must identify information relevant to goals and causes, two of Zwaan's and Radvansky's dimensions; that the woman sighed, and that her heart ached, not because her finger was sore or her apple spoiled, but because the experience seemed somehow relevant to her desire to have a child.

But the fine detail of the "irrelevant" information, I suggest, is important to emotion, and the role of emotion in processing. In combination, these elements configure an emotional experience which has no counterpart in the child's real life experiences of apples and knives, an experience which reveals that the woman's longing will be fulfilled because, in mysterious ways, nature wills it so.

We can illustrate this point in a different way by reverse engineering a segment of Zwaan and Radvanksy's illustration of the processing behind SMs - "Peter took the elevator to the fifth floor. He went to talk to his professor":

...When reading the first sentence, the reader creates a situation model involving a token that represents a male individual named Peter who rides an elevator for as yet unknown reasons. We assume that the reader infers that Peter is in a building and that the event took place before the moment of utterance of the sentence....This [second] sentence is integrated with the first one on several dimensions. First, the pronoun is a cue to the comprehender to look backward...in the integrated model for an appropriate referent. This referent is found in Peter, who is the only available referent and shares the feature "male". 
Second, a goal is constructed ("went to" suggests intentionality...). Third, the absence of a shift in tense or any other explicit temporal marker indicates that we are still in the same temporal interval... Fourth, the absence of a spatial marker indicates we are still in the same spatial region.... Fifth, a second token is created representing the professor. The reader probably also infers that Peter is a student. This is the content of the current model at Time $t_{2}$.

This can be represented schematically:

$t_{l}$ Create PETER ${ }^{\text {TOKEN (male) }}$

$t_{l}$ Create ELEVATOR IN BUILDING IN PAST ${ }^{\text {SPATIO-TEMPORAL FRAMEWORK }}$

$t_{l}$ Combine PETER ${ }^{\text {TOKEN (male) }}$ in ELEVATOR IN BUILDING IN PAST ${ }^{\text {SPATIO-TEMPORAL FRAMEWORK }}$

$t_{2}$ Create PROFESSOR ${ }^{\text {TOKEN (male) }}$

$t_{2}$ Modify PETER ${ }^{\text {TOKEN (male) }}$ with GOAL ${ }^{\text {VISIT PROFESSOR }}$ and with ${ }^{\text {(student) }}$

$t_{2}$ Incorporate $t_{2}$ elements with $t_{1}$ elements.

If we use this set of instructions to generate a new text, one possibility of many is this:

"Peter rode in the elevator up, up, up. His professor waited as Peter came nearer and nearer." This text is different from the initial one in many ways, from the professor waiting, to the absence of "the fifth floor". But it is as compatible with the situation model above as the original. The reader's emotion, however, is likely to be different. The stylistic emphasis on the changing relative distance between Peter and the professor may create an element of anxious anticipation. Emotion arising from verbal form may underpin the inference of information, rather than the reverse (compare Barrett and Bar, 2009). The verbal form suggests that either Peter or the Professor has 
something to fear from the encounter. Peter's goal may not be related to their roles of student and professor; Peter may not be a student at all if his relationship to the professor may be that of, say, victim or aggressor. The repetitions of "up" and "nearer" do not provide new information on the SM's dimensions. Yet their emotional impact on the reader is important for identifying precisely the information - such as characters' goals - which an SM is intended to capture. While the SM itself need not capture reader emotion, the processing leading up to it must if the information in the $\mathrm{SM}$ is to be correct (for earlier work pointing in this direction, see McNamara \& Magliano, 2009 and Graesser, Olde \& Klettke 2002).

Suppose the repetitions in "up and up" and "nearer and nearer" cause fear, telling the reader that either Peter or the professor has a sinister goal. Could this simply mean a different "goal" node than the model of the first passage? The spatiotemporal information still models Peter in an elevator and the professor in a room, just as in the first case.

But if the repetitions of "up" and "nearer" simply switch the goal node from "visit professor, probably in relation to studies" to "go to professor's room, not clear why, but this may involve danger either to Peter or the professor", does this bundle of information, a bundle which must be expanded if it is to include all the implications of fear, deserve the name of "goal node"? Recall that the strength of SMs is saving the hearer or reader from remembering not only all the verbatim text, but all of the information conveyed by that text. If the model is to incorporate all the implicit information generated by emotion, it will be burdened with even more information than that of the verbatim text. If emotion is treated as information encoded in the text, then it cannot be incorporated in an SM. Yet, as we have seen, emotion may be crucial to help a child make correct inferences about texts like The Juniper Tree. An 
improved account of narrative processing, then, will be holistic in its approach to information, and distinguish more clearly between the experiential aspects of perceiving something, and those of hearing or reading about it.

A first step is to rethink the processing behind SMs as structured not by five or six common sense dimensions, but by dimensions too many to enumerate, resisting commonplace psychological categorisation. A neural network model of processing in this high dimensional vector space (explained below) can capture recurring experiences in processing a given text, including the effects of verbal patterning, emotion and the perception of language as agent guided behaviour. Characterising those recurrent, downward projections as predictive can also suggest a convincing story about immersion in a flow of inner states, and explain overlaps in phenomenology between dreaming and narrative immersion.

\section{$\underline{\text { High dimensional vector spaces and verbal narrative }}$}

Think of a word as a sequence of sounds, where each sound has the potential to differentially activate every cell in an array. Each phoneme will come to be associated with a different pattern, or vector, of activation. The array activates another, higher, array through a set of connecting links or synapses, which in turn activates the next, and so on. The varying strengths or weights of these connections between layers have been determined by past experience, and form matrices which transform the vectors and allow recognition of groups of sounds, then words, phrases, clauses, sentences and so on (Rumelhart \& McClelland, 1986; Churchland, 2012; Jordan, 1986).

As well as these upward connections, each array has downward connections to the one below. This means that the effect of one input on the system can affect the way the next input is received, so that frequently repeated sequences of inputs are 
more easily recognised than others (Churchland, 2012, pp.165-170). At a certain level or levels, the points in the vector space initially activated by speech sounds move into spaces generated by a much wider range of stimuli associated with those speech sounds. On hearing the sounds for the word "apple", for example, a processing journey begins which, depending on the context, may end in an area of vector space overlapping, though not identical with, that activated by seeing a real apple (Reddy et al, 2010).

Now let us revisit The Juniper Tree. How does the hearer make the link between the interactions of a cluster of concepts (juniper, apple, blood, snow), the emotion associated with those interactions, and a character's conception of a longed for child? At first blush, adopting a vector space framework takes us no further forward with this problem. The world model of interacting causes built into this framework is embedded in the matrices of connection weights, and altering these weights is a slow and cumulative process, a matter of weeks or years, not the seconds or fractions of seconds involved in responding to a section of a story. How can hearing a brief text, or fragment of text, temporarily modify these weights to accommodate a different analysis, one in which cut fingers activate representations involving beauty and yearning rather than pain and distress, for example?

One possibility is that instead of modifying the matrices of weights, the recurrent, downward connections can modify the stream of inputs. In the case of The Juniper Tree, all of the effects of the text to date influence the pattern of downward connections in ways that affect the upward impact of new inputs. The succession of states and their direction of travel form a trajectory through vector space. In what follows, I suggest that verbal narratives can stimulate trajectories of this kind that 
depart from normal perceptual experience, while staying within the bounds of a preexisting world model.

Behavioural, neuro-psychological and neuroimaging evidence suggests that “concepts are flexible, distributed representations comprised of modality specific conceptual features" (Kiefer and Pulvermüller 2012, 805). This flexibility is consistent with accounts by Paul Churchland and Margaret Boden characterising the reconceptualization of an input in the "hidden" layers of a neural network as a creative process. Each cycle of Newton's meditations on the moon could modify his existing concept a little more, until the moon is less like a wheel running on a track and more like a ball thrown by a force (Churchland 2012, pp.187-196; Boden 2004). The everyday experience of narrative text may similarly push us through otherwise unfamiliar trajectories in vector space.

\section{$\underline{\text { Vector spaces and inference }}$}

The extract from The Juniper Tree, typically of fairy tales (Thompson, 1946, p.8), provides minimal information about particulars of place or time. The event happened "once" and "in winter time" rather than on, say, 4 January 1822. The time, then, is indeterminate, as are the unmodified nouns "woman", "tree", "apple" and so on. Adjectival modification affects the ways in which nouns are processed (Westerlund et al, 2015; Bemis \& Pylkkänen, 2013). Each of the unmodified concrete nouns in this case, then, could potentially activate an area of vector space associated with a prototypical representation (of women, trees, apples and so on), areas which capture averages of similarity and difference across multiple dimensions, thus enabling real life recognition of a particular woman, tree or apple by its location relative to the average. Coming as they do in a sequence, the downward, recurring connections generated by these nouns create a context in which singular entities (the 
particular woman, tree, apple of the story) are reconceptualised as prototypical ones (compare the comments on style and prediction in Kuperberg \& Jaeger, 2016, p.48). The later nouns "blood" and "snow" arrive in, and reinforce, a landscape of prototypes. A real life encounter with objects and people that all coincided precisely with the average of their type might create a sense of the uncanny, and "seemingly invite a supernatural explanation" (Bouvet and Bonnefon, 2015, p. 956).

A second contextual effect could arise from repeated syntactic patterns. The text consists mainly of additive clauses - "and as she was peeling... and the blood fell...and she looked... and her heart ached" - with little of the subordination ("she cut her finger causing the blood to fall", "her heart ached because...") that can point directly to causal relationships (Morera et al, 2017). In perception, a repeated temporal sequence can have a strong, sometimes misleading, association with causality (Churchland, 2012, pp.177-178). However, the recurrent connections generated by a repeated syntactic pattern of additive clauses could undo this because the hearer is not free to probe causation as she would in a richer environment.

By contrast, perception of a scene like this in a real world, rich environment would be structured by causal relationships. The appearance of the woman would be modulated by effects of light and shadow caused by the tree and the snow (Kersten et al 1997). Spatial structure has long been understood as important to perceiving causal narrative structure (Heider 1944), just as internal scene construction is critical to both episodic memory and verbal narrative (Mullally et al 2012). In this case, in the absence of a causal structure relating many of the elements in the scene, and in a landscape of syntactically weakened causal links, other patterns of similarity and difference can interpret the relationships between inputs. The tastes and textures of apples, for example, and the texture and temperature of snow could be located in 
adjacent or overlapping areas of vector space, as multisensory integration (Stein et al, 1988) is released from the constraints imposed by real world stimuli. The pain of a cut might be measured against the colour and temperature of blood. In a real world scene these modality specific overlaps may be unimportant, but here, in a sparser, less defined scene, they take on new power. The synaesthetic effects of this process would, moreover, have an aesthetic reward (Ward et al, 2008).

Now let us imagine that the hearer has had many disappointed hopes, but has also experienced a powerful hope turning into a belief. The move from hope to belief, then, is a possible sequence for her, but not a necessary one. In a context coloured by the uncanny and by aesthetic reward, a context in which normal causal relations have been muted, this sequence (of hope turning to belief) may become the most likely path for upcoming activation (compare Clark, 2016, pp.231 - 237). The hearer can hypothesise that the woman sighs because of longing, not physical pain, without modifying her world model's matrix of weights.

\section{A vector space account of narrative coherence}

In 1990, the cognitive scientist Jeffrey Elman discussed the problems of representing time in parallel, distributed, connectionist models of cognition, similar to the neural networks outlined above. Until then, Elman explained, a common approach to the parallel processing of sequentially structured inputs, like language, had been to treat time as "an additional dimension of the input" by giving it an explicit "spatial representation". The first item in a verbal sequence could be represented in the first space in a vector, and so on. Elman argued that this approach runs into intractable problems (which I do not discuss here; Elman, 1990). Time is an explicit dimension of the input to SMs in existing accounts: a complete SM, 'stored in long-term memory after all the textual input has been processed' will consist of 'the situations at Times $\mathrm{t}_{1}$ 
through $t_{x}$ ', allowing comprehenders to 'ruminate over a story' later (Zwaan \& Radvansky 1998, 166). While not described as a spatial representation in the form of a numerical matrix, this is an approach which makes time an explicit dimension in both processing (one of the five associated with SMs) and output (the SM itself). Instead of treating time as a dimension of the input, Elman suggested instead an implicit representation of time in which a layer of "context" cells is added to the layers of "hidden" cells. At time $t$ :

Both the input units and context units activate the hidden units; the hidden units then feed forward to activate the output units. The hidden units also feed back to activate the context units- (Elman 1990, p.182).

The context units modify future inputs by responding to previous inputs. In this way, time can be represented through its cumulative effects "on processing and not as an additional dimension of the input".

A "spatial metaphor for time" of the kind identified by Elman as problematic is implied by the SM's linear structure from $t_{1}$ to $t_{x}$, which ensures coherence, letting the reader 'know when the described events took place both relative to each other and relative to the time at which they were narrated'- (Elman, 1990, p.181; Zwaan \& Radvansky, 1998, p.181).- But are such representations of time always essential to the processing that enables SMs? If I am asked to write a reference, I might try to recall specific instances of the candidate's past behaviour. However, if I predict what my friend will order at a restaurant, I need not bring to mind all or any of the past episodes underwriting that prediction, even if I could. To test narrative comprehension, researchers need to resolve the experience of verbal narrative into 
actions after the event, such as answering questions about a story accurately, or retelling it (Ennemoser 2007, p. 354; Strong 1998). One way to describe this is the ability to interrogate the SM which arose from processing the narrative.

But there is another way to think about, and potentially even measure, verbal narrative comprehension: the success of a cognitive system in continually moving towards stasis in response to an incoming flow of text (Spivey, 2007, p.36 and elsewhere). A child hearer could experience this move to stasis yet still perhaps be unable, if asked, to accurately reconstruct a timeline of the story or answer questions accurately. Even scrub jays can "remember" sequences of their own actions without, presumably, being able to represent those sequences to themselves or to others (Clayton and Dickinson 1998, 1999; Suddendorf and Busby, 2003). As Elman points out, "The representation of time - and memory - is highly task-dependent". A potentially explicit spatial representation of time may be essential to the task of reproducing a story. But it is not necessarily essential to experiencing the flow of verbal narrative as coherent.

The Juniper Tree continues with the woman's pregnancy, her death from happiness on giving birth, and her husband's remarriage:

By the second wife he had a daughter, but the child of his first wife was a little son as red as blood and as white as snow. Now when the woman looked at her daughter she loved her so, but looking at the little boy cut her to the heart.

Not long after, the stepmother kills the boy and hides the evidence by cooking the body parts in a stew. The text never refers to her as "the stepmother" but as "the woman" or, when addressed by the boy himself, "mother": "Mother," said the little 
boy, "how strange and wild you look!". To avoid confusion with the real mother, and experience the story as coherent, the child hearer must remember that the real mother died and was replaced by a wicked stepmother. One solution is to tag the mother's death and the stepmother's arrival as $t_{x}$ and $t_{x+1}$, ready for incorporation in an SM by situating them on a timeline. But the child's experience of the text as coherent can be explained without this explicit representation of time:

\begin{abstract}
And so the mother took the little boy and hacked him in pieces and put the pieces in the pot and stewed him in the sour broth. But Ann Marie stood by and cried and cried and the tears fell in the pot so that it didn't need any salt.

When the father came home he sat down to supper and said, "And where is my son?" And so the mother brought a big dish of black stew and Ann Marie cried and couldn't stop crying.
\end{abstract}

I argued above that the real mother could be generated in areas of vector space which involved the uncanny and the aesthetic effects of synaesthesia. The stepmother, on the other hand, is developed through "taking" and "hacking", and the objects surrounding her are "the pot" and "the sour broth", reinforced soon after as "a big dish" and "black stew". The difference in the areas of vector space activated in each case mean that neither a timeline of death and remarriage, nor a consistent verbal distinction between "mother" and "stepmother", are needed for the child hearer to experience the text as coherent. Indeed, at this point in the story she need not even explicitly remember that there ever was a good mother. After all, many stories, including oral epic and medieval romance, are experienced as coherent even when found, after performance, to be incoherent and flawed by "continuity errors" (Griffith, 2012). 


\section{A predictive, vector space account of narrative immersion}

There is growing evidence that language comprehension is predictive at every level, from phonemes and words to discourse. Probabilistic processing, for example, can pre-activate words in comprehension (Delong et al, 2005). Grammatical inflections can be anticipated through semantic integration, and word meanings can be predicted on the basis of discourse context (Wicha et al, 2004; Van Berkum et al, 2005; Otten and Van Berkum, 2008). These findings are drawn from different languages, multiple linguistic levels and using varied methodologies (Kamide et al, 2003a; Kamide et al, 2003b; Knoeferle et al, 2005).

We can, then, characterise the downward connections discussed above as predictions about the incoming verbal signal (Clark, 2016, 285-286). In a PP framework, downward hypotheses are met by upward prediction error. Patterns of prediction error simultaneously modify the next wave of downward hypotheses and allocate precision, or increased weight, to the most reliable sources of error for the task at hand. Action is integral to this cycle of hypotheses, prediction error and precision allocation, through, for example, eye saccades.

One outcome of a move to PP, or hypothesising controlled by prediction error (Clark, 2016), is a new account of relationships between cognitive states such as dreaming, hallucination, delusion and imagination (Gerrans, 2014, p.-1; Kirchhoff, 2018; Seth, 2014, p.101). In what follows I characterise hearing or reading a narrative as a cognitive state in which prediction error is limited to the incoming verbal stream, so that the hearer or reader, to successfully predict the incoming signal, must predict her own inner states, sequestering her sensorimotor responses from the machinery of the world around her. 
Actions to probe the environment can help the hearer to predict the stream of words in The Juniper Tree only to a limited extent. Perhaps the storyteller has a lisp, and she must compensate for this when predicting phonemes, or perhaps he uses particular gestures in their shared space, and her predictive system might direct saccades to his face and body (Lwin, 2010). But greater attention to arm movements and sound articulation will not help her predict the states of higher levels in her own system, such as the combined effects of synaesthesia and the uncanny identified above. For these, her best - indeed her only - source of information is the trajectory of inner states arising from the experience of the text itself. It is these higher-level inner states which must be explored and probed through the mechanism of precision weighting. The hearer's own states become her environment as far as predicting the text goes. In this light, the potential for immersion is not surprising.

Seen like this, narrative experience in one respect resembles dreaming. Both experiences engage the mind in actively predicting an incoming stream of data, but without the body being able to act on its environment to direct that stream. Hobson and Friston characterise sleep as a state "in which internal predictions are sequestered from sensory constraints" (Hobson and Friston, 2012, p.92).

Embodied responses to language suggest that the reader or hearer of narrative may similarly find her sensorimotor system engaged while sequestered from any stimulus but the verbal stream, and inhibited from acting on any stimulus but the verbal stream (for example by re-reading a sentence, or asking a reader to pause). Narrative comprehension then, might be characterised as simultaneously active, in the sense that the system has considerable work to do on internal states as it seeks to optimise prediction and achieve stasis, and passive, in that the body has only very limited opportunities to act on its environment in pursuit of that stasis, and must 
develop new trajectories from existing resources to account for the succession of internal states.

The analogy between narrative immersion and dreaming should not be overdone. Narrative stimuli are artefacts, dreams are not. Readers can re-read, but dreamers cannot pause and repeat a section of a stimulus. Narrative can engage and require conscious effort at problem solving in way that dreams cannot. And readers can stop at will. But shared constraints in the two conditions may explain at least some of the dream-like phenomenology of narrative immersion.

This account of immersion does not require hearers and readers to feel emotions for characters, as some existing theories of transportation do (Gerrig, 1993; Green \& Brock, 2002). Fairy stories like The Juniper Tree can be immersive, but do not necessarily encourage direct emotional responses to characters. Stock characters are central, not peripheral, to this and other oral genres (Propp, 2010; Lord, 2000). The same could be said of immersive responses to a range of other non-realist (in Barthes' sense of 'the reality effect'; 1986) fictions, which some readers/hearers find immersive, from Homer to Virginia Woolf.

The sketch above does not assume immersion always happens, just as existing models do not assume that comprehension always happens. Some stories, or some readers, might reveal an easy to predict causal structure involving little emotion, so that attention wanders. With others, prediction might be too hard to permit flow, at least on a first reading (Csikszentmihalyi, 1990). But a predictive account can explain the possibility of later immersion through practice and re-reading, as readers grow more expert at predicting a text, like Joyce's Ulysses (a tough first read for many, an immersive re-read for some), an author or a genre (Kibbe et al, 2017).

$\underline{\text { Problems }}$ 
There are potential problems in at least three areas: the cognitive framework; a role for conscious reflection; and empirical testing.

I have drawn on Clark's (2016) account of Bayesian predictive processing implemented in a neural network. Clark himself has identified some problems with both elements (pp.297-300). Alternative approaches to probabilistic inference have been explored in both neural simulations and in studies of the biological brain (Egner \& Summerfield, 2013). Neural networks may not be the best, or even a possible, architecture for a generative, probabilistic approach to cognition (Hinton, 2006; Wacongne et al, 2012).

Another concern is the role of higher domain areas, such as conscious verbal reasoning, in probabilistic, generative predictive processing (pp.299-300). I have argued that implicit, rather than explicit, representations of time may be enough to support at least some narrative processing. But conscious reflection on narrative experience may be needed to retell, interpret and experience stories as meaningful and instructive. Reducing the role of reflection may mean missing some of the point of narrative in the first place (Mulhall, 2007; Malinowski, 1926).

A third issue concerns making and testing predictions. Spivey and others have pioneered methods to measure language processing in real time (Spivey, 2007, pp.7477). In combination with real time measures of affect, these could test predictions about how, for example, affect guides hearers towards inferences in narrative processing. Rapid advances in the verbal classification of images by neural networks suggest that upending these networks to produce images from text (as readers do) may reveal surprising implicit causal frameworks (Mordvintsev, 2015).

$\underline{\text { Conclusion }}$ 
Describing narrative experience in a PP, neural network framework reveals that the range of benefits we reap from stories may be both more subtle and more widely diffused than we realise. Narrative experience may be a highly creative process, reconceiving the world as recognisable, yet with a different causal structure to that in which we live and move and have our being.

\section{$\underline{\text { References }}$}

Aarne, A. and Thompson, S. (1928). Types of the Folktale. Helsinki: Suomalainen Tiedeakatemia.

Barrett, L.F. \& Bar, M. (2009). See it with feeling: affective predictions during object perception. Philosophical Transactions of the Royal Society B, 364, pp.1325-1334.

Barthes, R. (1989). The reality effect. In Hale, D.J. (Ed.) \& Howard, R. (Trans.), The Novel: an anthology of criticism and theory 1900-2000. Oxford: Blackwell.

Barsalou, L. (2008). Grounded cognition. Annual Review of Psychology, 59, pp.617645.

Bauman, R. (1986). "I go into more detail now, to be sure"; narrative variation and the shifting contexts of traditional storytelling. In Story, Performance and Event. Cambridge: Cambridge University Press. Chapter five.

Bemis, D.K. \& Pylkkänen, L. (2013). Basic linguistic composition recruits the left anterior temporal lobe and left angular gyrus during both listening and reading. Cerebral Cortex, 23 (8), pp.1859-1873.

Berlyne, D. 1960. Conflict, Arousal and Curiosity. New York: McGraw-Hill.

Berlyne, D. 1971. Aesthetics and Psychobiology. New York: Appleton-CenturyCrofts.

Blumenthal, A. (1967). Prompted recall of sentences. Journal of Verbal Learning and Verbal Behavior, 6, pp.674-675.

Boden, M. (2004) [1990], The Creative Mind: myths and mechanisms. Routledge, London.

Bouvet, R. \& Bonnefon, J. (2015). Non-reflective thinkers are predisposed to attribute supernatural causation to uncanny experiences. Personality and Social Psychology Bulletin, 4, pp. 955-961.

Bransford, J.D., Barclay, J.R. \& Franks, J. J. (1972). Sentence memory: a constructive versus interpretive approach. Cognitive Psychology, 3, pp.193-209. 
Brewer, W. F. \& Lichtenstein, E. H. 1982. Stories are to entertain: a structural-affect theory of stories. Journal of Pragmatics, $6473-486$.

Chow, H.M., Mar, R.A., Xu, Y., Liu, S., Wagage, S. \& Braun, A.R. (2014).

Embodied comprehension of stories: interactions between language regions and modality-specific neural systems. Journal of Cognitive Neuroscience, 26, pp.279-295.

Churchland, P.M. (2012). Plato's Camera: how the physical brain captures a landscape of abstract universals. Cambridge Mass: MIT Press.

Clark, A. (2013). Expecting the world: perception, prediction and the origins of human knowledge. Journal of Philosophy, 110, pp. 469-496.

Clark, A. (2016). Surfing Uncertainty: prediction, action and the embodied mind. Oxford University Press, Oxford.

Clayton, N.S. \& Dickinson, A. (1998). Episodic-like memory during cache recovery by scrub jays. Nature, 395, pp. 272-278.

Clayton, N.S. \& Dickinson, A. (1999). Scrub jays (Aphelocoma coerulescens) remember when as well as where and what food item they cached. Journal of Comparative Psychology, 113, pp. 403-416.

Csikszentmihalyi, M. (1990). Flow: the psychology of optimal performance. Cambridge: Cambridge University Press.

Cutting, J., Brunick, K., DeLong, J., Iricinschi, C. \& Candan, A. 2011. Quicker, faster, darker: changes in Hollywood film over 75 years. $i$-Perception, 2, pp.569576.

Delong, K.A., Urbach, T.P. \& Kutas, M. (2005). Probabilistic word pre-activation during language comprehension inferred from electrical brain activity. Nature Neuroscience, 8, pp. 1117-1121.

Egner, T, \& Summerfield, C. (2013). Grounding predictive coding models in empirical neuroscience research. Comments on Clark, A. (2013). Whatever next? Predictive brains, situated agents, and the future of cognitive science. Behavioral and Brain Sciences, 36. pp.210-211.

Elman, J.L. (1990). Finding structure in time. Cognitive Science, 14, pp. 179-211.

Ennemoser, M. \& Schneider, W. 2007. Relations of television viewing and reading: findings from a 4-year longitudinal study. Journal of Educational Psychology, 99 (2), $349-368$.

Fischer, M. H., and Shaki, S. (2014). Spatial associations in numerical cognitionfrom single digits to arithmetic. Quarterly Journal of Experimental Psychology, 67, pp. 1461-1483. 
Fiske, S., Dupree, C., Gandalf, N. \& Swencionis, J. (2016). Status, power, and intergroup relations: the personal is the societal. Current Opinion in Psychology, 11, pp. $44-48$.

Gerrans, P. (2014). Pathologies of hyperfamiliarity in dreams, delusions and déjà vu. Frontiers in Psychology, 5 (article 97). 1 - 10.

Gerrig, R. (1993). Experiencing Narrative Worlds. New Haven, CT: Yale University Press.

Gerrig, R.J. \& O’Brien, E.J. 2005. The scope of memory-based processing. Discourse Processes, 39, pp.225 - 242.

Gibson, J. (1966). The Ecological Approach to Visual Perception. Houghton Mifflin.

Glenberg, A., Meyer, M. \& Lindem, K. (1987). Mental models contribute to foregrounding during text comprehension. Journal of Memory and Language, 26, pp.69-83.

Glenburg, A.M. \& Kaschak, M.P. (2002). Grounding language in action. Psychonomic Bulletin and Review, 9, pp.558-565.

Graesser, A., Singer, M. \& Trabasso, T. (1994). Constructing inferences during narrative text comprehension. Psychological Review, 101, pp.371-395.

Graesser, A., Olde, B. \& Klettke, B. (2002). How does the mind construct and represent stories? In M. Green, J. Strange \& T. Brock, eds. Narrative Impact: social and cognitive foundations. Mahwah, NJ: Erlbaum. pp.229-262.

Green, M. \& Brock, T. (2002). In the mind's eye: imagery and transportation into narrative worlds. In M. Green, J. Strange \& T. Brock, eds. Narrative Impact: social and cognitive foundations. Mahwah, NJ: Erlbaum. pp.315 - 341.

Griffith, G. (2012). Merlin. In Cartlidge, N. (Ed.), Heroes and Anti-Heroes in Medieval Romance. Cambridge: D.S. Brewer. pp. 99-114.

Grimm, F. \& Grimm, W. (1973). In L Segal, L. \& Jarrell, R. (Trans.), The Juniper Tree and other tales from Grimm. London: Bodley Head.

Grimes, J. (1996). On the failure to detect changes in scenes across saccades. In Atkins, K.A. (Ed.), Perception, vol.5. Oxford: Oxford University Press.

Hauk, O., Davis, M.H., Kherif, F. \& Pulvermüller, F. (2008). Imagery or meaning? Evidence for a semantic origin of category-specific brain activity in metabolic imaging. European Journal of Neuroscience, 27, pp. 1856-66.

Hasson, U., Landesman, O., Knappmeyer, B. Vallines, I., Rubin, N. \& Heeger D. 2008. Neurocinematics: the neuroscience of film. Projections, 2 (1), pp.1-26. 
Heider, F. 1944. Social perception and phenomenal causality. Psychological Review, 51 (6), pp.358-374.

Henderson, J.M. (2003). Human gaze control in real-world scene perception. Trends in Cognitive Sciences, 7, pp.498-504.

Hinton, G.E., Osindero, S., \& Teh, Y. (2006). A fast learning algorithm for deep belief nets. Neural Computation, 18, pp.1527-1554.

Hinton, G.E., \& Salakhutdinov, R.R. (2006). Reducing the dimensionality of data with neural networks. Science, 313, pp.504-507.

Hobson, J.A. \& K.J. Friston, K.J. (2012). Waking and dreaming consciousness: neurobiological and functional considerations. Progress in Neurobiology, 98, pp. 8298.

Jajdelska, E. (2016). Being there yet not there: why don't embodied responses to literary texts jar with one another? Journal of Literary Semantics, 45 (1), pp. 1 - 20.

Johnson-Laird, P.N. (1983). Mental Models: towards a cognitive science of language, inference, and consciousness. Cambridge, Mass: Harvard University Press.

Jordan, M.I. (1986). An introduction to linear algebra in parallel distributed processing. In Rumelhart, D.E. \& McClelland, J.L. (Eds.), Parallel Distributed Processing, 2 vols., Cambridge, Mass: MIT Press. pp. 365-422.

Kamide, Y., Altmann, G.T.M. \& S. L. Haywood. (2003). The time-course of prediction in incremental sentence processing: evidence from anticipatory eye movements. Journal of Memory and Language, 49, pp. 133-156.

Kamide, Y., Scheepers, C. \& Altmann, G.T.M. (2003). Integration of syntactic and semantic information in predictive processing: cross-linguistic evidence from German and English. Journal of Psycholinguistic Research, 32, pp. 37-55.

Katz, J.J. \& Postal, P.M. (1964). An Integrated Theory of Linguistic Descriptions. Cambridge, Mass: MIT Press.

Keen, S. (2007). Empathy and the Novel. Oxford: Oxford University Press.

Kersten, D., Mamassian, P. \& Knill, D. (1997). Moving cast shadows induce apparent motion in depth. Perception, 26 (2), pp.171-192.

Kibbe, M., Kreisky, M. \& Weisberg, D. (2017). Young children distinguish between different unrealistic fictional genres. Psychology of Aesthetics, Creativity \& the Arts, 11 .

Kiefer, M. \& Pulvermüller, F. 2012. Conceptual representations in mind and brain: theoretical developments, current evidence and future directions. Cortex, 48, pp.805825 . 
Kintsch, W. (1977). On comprehending stories. In M.A. Just \& P.A. Carpenter (Eds.), Cognitive Processes in Comprehension. pp.33 - 62. New York: Psychology Press.

Kintsch, W. \& van Dijk, T. (1978). Cognitive psychology and discourse. Recalling and summarising stories. In W.U. Dressler, W.U. (Ed.), Current Trends in Text Linguistics. Berlin/New York: De Gruyter. Pp.61-80.

Kirchhoff, M.D. 2018. Predictive processing, perceiving and imagining: Is to perceive to imagine, or something close to it? Philos Stud [CHECK FULL NAME], 175, 751 767.

Knoblich, G., Seigerschmidt, E., Flach, R. \& Prinz, W. (2002). Authorship effects in the prediction of handwriting strokes: evidence for action simulation during action perception, Quarterly Journal of Experimental Psychology, section A, 55 (3), pp.1027-1046.

Knoeferle, P., Crocker, M.W., Scheepers, C. \& Pickering, M.J. (2005). The influence of the immediate visual context on incremental thematic role-assignment: evidence from eye-movements in depicted events. Cognition, 95, pp. 95-127.

Kuperberg, G. \& Jaeger, F. (2016). What do we mean by prediction in language comprehension? Language, Cognition and Neuroscience, 31 (1), pp.32 - 59.

Lord, A. 2000. The Singer of Tales. Cambridge, Mass: Harvard University Press.

Loschky, L., Larson, A., Magliano, J., \& Smith, T. 2015. What would Jaws do? The Tyranny of film and the relationship between gaze and higher-level narrative film comprehension. PLOS ONE. 10 (11). E0142474.

Lwin, S.M. (2010). Capturing the dynamics of narrative development in an oral storytelling performance: a multimodal perspective. Language and Literature, 19, pp.357-377.

Malinowski, B. (1926). Myth in Primitive Psychology, London: Keegan Paul.

Mandler, J.M. \& Johnson, N.S. (1977). Remembrance of things parsed: story structure and recall. Cognitive Psychology, 9, pp.111-151.

Mar, R. \& Oatley, K. (2008). The function of fiction is the abstraction and simulation of social experience. Perspectives on Psychological Science, 3 (3), pp.173 - 192.

McKoon, G. \& Ratcliff, R. (1998). Memory-based language processing: psycholinguistic research in the 1990s. Annual Review of Psychology, 49, pp. $25-42$.

McNamara, D. \& Magliano, J. (2009). Towards a comprehensive model of comprehension. In The Psychology of Learning and Motivation, Vol. 51, ed. Brian Ross. Burlington: Academic Press. 297 - 384.

Meyer, B.J. (1975). The Organization of Prose and its Effects on Memory. New York: North Holland Publishing Company. 
Miall, D. \& Kuiken, D. 1994. Foregrounding, defamiliarization, and affect: response to literary stories. Poetics, 22, pp.389-407.

Miall, D. \& Kuiken, D. 1999. What is literariness? Three components of literary reading. Discourse Processes, 28, pp.121 - 138.

Mitchell, D. \& Cusack, R. (2016). Semantic and emotional content of imagined representations in human occipitotemporal cortex. Nature Scientific Reports, 6, article 20232.

Mordvintsev, A., Olah, C. \& Tyka, M. (2015). Inceptionism: going deeper into neural networks. url: https:/research.googleblog.com/2015/06/inceptionism-going-deeperinto-neural.html. Consulted 12 July 2017.

Morera, Y., León, Escudero, I. \& Vega, M. (2017). Do causal and concessive connectives guide emotional expectancies in comprehension? A double-task paradigm using emotional icons. Discourse Processes, 54 (8), pp.583 - 598.

Morrow, D.G., Greenspan S.L. \& G.H. Bower. (1987). Accessibility and situation models in narrative comprehension. Journal of Memory and Language, 26. pp.165187.

Muijselaar, M.M.L. \& de Jong, P. (2015). The effects of updating ability and knowledge of reading strategies on reading comprehension. Learning and Individual Differences, 43, pp.111-117.

Mulhall, S. (2007). The mortality of the soul: Bernard Williams's character(s). In A. Crary (Ed.), Wittgenstein and the Moral Life: essays in honor of Cora Diamond Cambridge, Mass: MIT Press. pp.355-380.

Mullally, S., Intraug, H. \& Maguire, E. (2012). Attenuated boundary extension produces a paradoxical memory advantage in amnesic patients. Current Biology, 22. 261-268.

Newtson, D. (1973). Attribution and the unit of perception of ongoing behaviour. Journal of Personality and Social Psychology, 28, pp.28 - 38.

Norenzayan, A., Atran, S., Faulkner, J. \& Schaller, M. 2006. Memory and mystery: the cultural selection of minimally counterintuitive concepts. Cognitive Science. 30. 531-553.

Otten, M. \& van Berkum, Jos. (2008). Discourse-based word anticipation during language processing: prediction of priming? Discourse Processes, 45, pp. 464-496.

Overy, K. \& Molnar-Szakacs, (2009). Being together in time: musical experience and the mirror neuron sysem. Music Perception, 26, pp.489-504.

Propp, V. 2010. Morphology of the Folk Tale, trans. Laurence Scott, Austin: University of Texas Press. 
Rapp, D.N., Gerrig, R.J. \& Prentice, D.A. (2001). Readers' trait-based models of characters in narrative. Journal of Memory and Language, 45, pp.737-750.

Reddy, L., Tsuchlya, N. \& Serre, T. (2010). Reading the mind's eye: decoding category information during mental imagery. Neuroimage, 50, pp. 818-825.

Rumelhart, D.E. (1975). Notes on a schema for stories. In Bobrow, D.G. \& Collins, A. (Eds.), Representation and Understanding: studies in cognitive science. New York: Academic Press. pp.211-236.

Rumelhart, D.E. (1977). Understanding and summarising brief stories. In LaBerge, D. $\&$ Samuels, S.J. (Eds.), Basic Processes in Reading: perception and comprehension. Hillsdale, New York: Lawrence Erlbaum.

Rumelhart, D.E. and McClelland, J.L. (Eds.). (1986). Parallel Distributed Processing. 2 vols. Cambridge, Mass: MIT Press.

Sachs, J. (1967). Recognition memory for syntactic and semantic aspects of connected discourse. Perception and Psychophysics, 2, pp.437-442.

Sanford, A. \& Emmott, C. (2012) Mind, Brain and Narrative. Cambridge: Cambridge University Press.

Seth, A.K. (2014). A predictive processing theory of sensorimotor contingences: explaining the puzzle of perceptual presence and its absence in synesethesia. Cognitive Neuroscience, 5 (2), pp.97 - 118.

Smith, T. \& Henderson, J. M. (2008). Edit blindness: the relationship between attention and global change blindness in dynamic scenes. Journal of Eye Movement Research, 2, pp.1-17.

Speer, N.J., Zacks, J. \& Reynolds, J.R. (2007). Human brain activity time-locked to narrative event boundaries. Psychological Science, 18, pp. 449-455.

Speer, N.K., Reynolds, J.R., Swallow, K.M. \& Zacks, J.M. (2009). Reading stories activates neural representations of visual and motor experiences. Psychological Science, 20, pp. 989-999.

Spivey, M. (2007). The Continuity of Mind, Oxford University Press, Oxford.

Stanovich, K. \& West, R. (2000). Individual differences in reasoning: implications for the rationality debate. Behavioral and Brain Sciences, 23, pp.645 - 665 .

Stein, N.L. \& Glenn, C.G. (1979). An analysis of story comprehension in elementary school children. In Freedle, R.O. (Ed.), New Directions in Discourse Processing. Norwood, N.J: Ablex. pp.53-120.

Stein, B., Huneycutt, W. \& Meredith, M. 1988. Neurons and behaviour: the same rules of multisensory integration apply. Brain Research, 448, pp.355 - 358 . 
Sternberg, M. (1978). Expositional Modes and Temporal Ordering in Fiction. Baltimore, MD: Johns Hopkins University Press.

Sternberg, M. (2003). Universals of narrative and their cognitivist fortunes (I). Poetics Today, 24, $297-395$.

Strong, C.J. 1998. The Strong Narrative Assessment Procedure. Eau Claire, WI: Thinking Publications.

Suddendorf, T. \& Busby, J. (2003) Mental time travel in animals? Trends in Cognitive Sciences, 7, pp. 391-396.

Tan, E.S. (1994). Story processing as an emotion episode. In H. Van Oostendorp \& R.A. Zwaan, eds. Naturalistic Text Comprehension. Norwood, N.J.: Ablex, 167 188.

Tehrani, J.J. (2003). The phylogeny of Little Red Riding Hood. Plos One, 8, pp. 1-11.

Thompson, S. (1946). The Folktale. New York: Holt, Rinehart and Winston.

Thompson, S. 1955-1958. Motif-Index of Folk Literature. 6 vols. Bloomington: Indiana University Press.

Thorndyke, P.W. (1977). Cognitive structures in comprehension and memory of narrative discourse. Cognitive Psychology, 9, pp.77-110.

Trabasso, T. \& Wiley, J. (2005). Goal plans of actions and inferences during comprehension of narratives. Discourse Processes, 39, pp.129- 164.

Turi, J. (1931). Turi's Book of Lappland. Ed. and translated into Danish by E.D. Hatt, translated from Danish by E.G. Nash, Jonathan Cape, London and Toronto.

Van Berkum, J.J.A., Brown, C.M., Zwitserlood, P., Kooijman, V. \& Hagoort, P. (2005). Anticipating upcoming words in discourse: evidence from ERP's and reading times. Journal of Experimental Psychology: learning, memory, and cognition, 31, pp. 443-467.

Van Dijk, T.A. (1977). Semantic macro-structures and knowledge frames in discourse comprehension. In M.A. Just \& P.A. Carpenter (Eds.), Cognitive Processes in Comprehension (pp.3-32).

Van Dijk, T.A. \& Kintsch, W. (1983). Strategies in Discourse Comprehension, New York: Academic Press.

Wacongne, C., Changeux, J.-P. \& Dehaene, S. (2012). A neuronal model of predictive coding accounting for the mismatch negativity. Journal of Neuroscience, 32, 36653678 . 
Ward, J., Thompson-Lake, D., Ely, R. \& Kaminski, F. (2008). Synaesthesia, creativity and art: What is the link?. British Journal of Psychology, 99, pp. 127-141.

Westerlund, M., Kastner, I., Al Kaabi, M., Pylkkänen. (2015). The LATL as locus of composition: MEG evidence from English and Arabic. Brain \& Language, 141, pp.124-134.

Whitehead, W. (1999). Supporting Language and Literacy Development in the Early Years. Maidenhead: Open University Press.

Wicha, N.Y., Moreno, E.M. \& Kutas, M. (2004). Anticipating words and their gender: an event-related brain potential study of semantic integration, gender expectancy, and gender agreement in Spanish sentence reading. Journal of Cognitive Neuroscience, 16, pp. 1272-1288.

Zacks, J., Tversky, B. \& Iyer, G. (2001). Perceiving, remembering and communicating structure in events. Journal of Experimental Psychology: General, 130 , pp. $29-58$.

Zacks, J.M., Speer, N.K., Swallow, K.M., Braver, T.S. and Reynolds, J. R. (2007). Event structure in perception and conception. Psychological Bulletin, 127, pp.3-21.

Zacks, J.M., Speer, N.K. \& Reynolds, J.R. (2009). Segmentation in reading and film comprehension. Journal of Experimental Psychology: general, 138, pp.307-327.

Zacks, J.M. (2015). Flicker: your brain on movies. Oxford: Oxford University Press.

Zwaan, R., Langston, M.C. \& Graesser, A.C. (1995). The construction of situation models in narrative comprehension: an event-indexing model. Psychological Science, 6, pp. 292-297.

Zwaan, R., Magliano, J.P. and Graesser, A.C. (1995). Dimensions of situation model construction in narrative comprehension. Journal of Experimental Psychology:

learning, memory, and cognition, 21, pp.386-397.

Zwaan, R.A. \& Radvansky, G.A. (1998). Situation models in language comprehension and memory. Psychological Bulletin, 123, pp. 162-185.

Zwaan, R.A. (2009). Embodied cognition, perceptual symbols, and situation models, Discourse Processes, 28, pp. 81-88. 